\title{
5. Repetition, Reiteration, and Reenactment: Operational Detection
}

\begin{abstract}
Chapter 5 studies the film serials of the 1920s, a so far uninvestigated decade of film serial production, with a focus on operational detection. The Hope Diamond Mystery (Kosmik, 1921), The Power God (Davis, 1925), Officer 444 (Goodwill, 1926), and the sound serial Radio Patrol (Universal, 1937) repeat footage, reiterate, or reenact instances and thereby self-consciously foreground formulaic narrative structures and practices of recycling. These circular recurrences of anecdotes encourage viewers to compare and contrast scenes and frames, enabling them to identify a serial's theme, its central concerns, or to detect its crime. All of these exemplary serials mobilize forms of repetition to enable viewers to detect a theme or enigma, both fostering and rewarding acts of operational detection. The chapter details how, in encouraging operational detection, serials offer their viewers a subject position that is located at the nexus of immersion, self-reflexivity, and embodiment.
\end{abstract}

Keywords: Repetition, seriality, operational detection, anecdotal storytelling, film serials of the 1920 s

In investigations such as we are now pursuing, it should not be so much asked "what has occurred", as "what has occurred that has never occurred before". (Poe 1841a: 422)

Viewers of film serials can be compared to detectives who continuously observe, multiple times, but always carefully, a process that is not yet completed and that at times defies coherence. The task of the spectator-detective is to correlate and conjecture, to detect the correspondences, and to draw the connections that define the cause-and-effect relationships between individual narrative and visual fragments within a film serial. Taken from

Brasch, I., Film Serials and the American Cinema, 1910-1940: Operational Detection, Amsterdam University Press, 2018.

DOI: 10.5117/9789462986527/CHO5 
Benjamin's conceptualization of the detective as a subcategory of the flâneur in the Arcades Project to the much more mediated realm of cinematic experience, ${ }^{1}$ the viewer-detective's film reception takes into account the narrative and the technological affordances of the cinematic medium, as viewers connect both story fragments and the segments of film, that is, individual frames, scenes, or entire episodes of a serial. Film serials thus engage their viewers in a task that I call 'operational detection'. In a sense, operational detection reverses the investigative approach proposed in Edgar Allan Poe's 'The Murders in the Rue Morgue'. Traditional detective stories such as Poe's evolve around an enigma to be solved and a capable (though amateur) investigator to solve it. They respond to modernity's increase in acceleration, contingency, and anonymity by casting the detective as an organizer who, often retrospectively, combines individual observances into a coherent whole. In film serials, by contrast, crime and pursuit take place almost simultaneously, and the pursuers frantically and chaotically follow the developments instead of serving as correlational anchors (Mayer 2017:21-22). The actual efforts to correlate and to make sense of the action on screen is relegated to the viewers, who take on the task of detection. In the serialized cinematic format, which defers resolution to the final episode, detection assumes an operational quality: the viewers' investigative efforts serve to make sense of ongoing processes, from episode to episode. Operational detection then describes their act of identifying correspondences, that is, repetitions, reiterations, and reenactments. This is why the viewers' approach to detection is the reverse of Detective Dupin's task in 'The Murders of the Rue Morgue': film serial audiences specifically ask 'what has occurred that has occurred before?'

This chapter will delineate operational detection as a subject position and mode of reception in four case studies: in the silent-era serials THE Hope Diamond Mystery (Kosmik, 1921), OfFicer 444 (Goodwill, 1926), and The Power God (Davis, 1925), and in the sound-era police serial RAdio Patrol (Universal, 1937). All of these serials offer thrilling film experiences within framing narratives that are propelled onwards from episode to episode but that are also highly repetitive. Instead of aiming to obscure repetition, these serials employ it in ways that correspond to the more generally presentist and presentational character of film serials as outlined in chapter three. Their narrative and visual references of earlier instances within the same serial encourage viewers to draw connections and compare scenes

1 For a more detailed account of film serial viewers as detectives, see chapter four of this volume. 
beyond the chronological succession of episodes. Such references occur on various levels, which I will distinguish by referring to them as repetitions, reiterations, or reenactments. Each episode of a serial repeats basic narrative information to help audiences understand the plot and remind them of important character constellations, and it usually also repeats part of the cliffhanger of the preceding week. Additionally, many serials and their individual episodes reiterate narrative information, themes, or discourses from media outside of this particular film. The four examples, moreover, reenact instances from their own previous installments, providing near duplicates of earlier scenes that encourage comparison and contrasting. Especially these latter instances of reenactment, as I will show, capitalize on and foster operational detection, and they encourage the viewers' reflexive engagement with serial storytelling.

Serials employ repetition, reiteration, and reenactment to evoke affective impulses and, over time, to intensify affect by reinstating and pressurizing particular emotional states. As a side effect, serials thereby challenge established paradigms of film viewing. They invite and reward a mode of reception that is more detached than immersion but also more engaged than a film experience in the form of Brechtian alienation. Moreover, operational detection places film serials at the conceptual threshold of a 'cinema of attractions' and 'classical Hollywood.' Therefore, before illustrating operational detection in film serials of the 1920 and 1930s, I will take a step back and detail the possible effects of various filmic forms of reprise for the viewer. First, I will show how repetition and correlation were pivotal to the transformation of the filmic medium from sensational apparatus to transparent conveyor of moving images, and thus explain the situation of operational detection between the conceptual extremes of immersion and alienation, which particularly informs film serials. Second, I will relate the serials' use of repetition, reiteration, and reenactment to their indebtedness to melodrama as a body genre. The serials' exhibitionist uses of the three forms of reprise foster affect in ways that self-consciously stress the embodied over the immersed viewer. Therefore, in order to illuminate how filmic forms of reprise help to invoke the viewers' affective responses, I will take cues from the study of another body genre: pornography, arguably one of film's most repetitive and reiterative of genres.

This conceptual framework will enrich the passages afterwards, which illuminate how The Hope Diamond Mystery, Officer 444, The Power God, and RADIO PATROL each resort to repetition, reiteration, and reenactment to evoke physical sensations and to engage their audiences in a reception experience that is both emotionally and analytically engaging. 


\section{Contemplation, Immersion, and Body Genres}

Historically, film serials emerged as a part of what has been termed transitional cinema (Hansen 1994). However, rather than recognizing the transitional period in terms of a shift in which the earlier form - the cinema of attractions (Gunning 1986) - was replaced by its successor, classical Hollywood, the following pages consider film's transition to be a shift from one mainstream to another, in which both filmic styles and their respective modes of engagement continue to exist. Within their early years and throughout the studio era, film serials combined elements of both. When considered not as chronologically superseding eras of filmmaking but as two distinct cinematic styles, the 'cinema of attractions' and 'classical Hollywood' can be imagined as constituting two ends of a scale along the lines of which individual films can be aligned-regardless of their respective dates of production. Defined as such, both film styles provide vocabulary that helps to sketch the cinematic style of and mode of engagement with film serials.

Tom Gunning determines the years between 1895 and 1907 as the period of the 'cinema of attractions' - a time when the fascination of film viewing rested on the spectacular novelty of the apparatus and on the fact that it enabled the projection of moving images (cf. 1986, see also chapter two of this volume). Films were mostly shown as a part of variety shows, which contrasted their technological projection with live acts such as vaudeville sketches and sing-alongs. This method of programming foregrounded film's mediality, and the films themselves incorporated a corresponding notion of display when actors directly faced the camera or through trick filming, which particularly exemplified the possibilities of the new form. These films invited their audiences to engage with cinema as an opaque medium instead of immersing them in a narrative world. Nevertheless, as Shane Denson asserts, an audience's appreciation of a visual trick or their surprise about an actor's look at the camera depend on the 'referential potential' of the filmic medium, that is, on the knowledge that film has the capacity to immerse its spectators in a narratively enclosed fictional environment. Therefore, the equation of the cinema of attractions and medial opacity and its juxtaposition against a 'classical Hollywood' that casts the filmic medium as fully transparent is by no means absolute or accurate, but a mere simplification (Denson 2014a: 63-66).

Nevertheless, early film bears a tendency towards opacity that was inverted by 1917 (Denson 2014a: 66). Classical Hollywood cinema, the kind described by Bordwell, Thompson, and Staiger as firmly in place by then, 'idealizes absorption into the diegetic world' (Denson 2014a: 6o; cf. Bordwell, 
Staiger, \& Thompson 1985). Instead of engaging with the filmic medium, spectators now watch particular films, which often direct less attention to their own technological mediation. Viewers are no longer concrete beings sharing a physical theater space with the cinematic apparatus; they are film's 'implied spectator', an abstraction devoid of gender, class, race, or physiological differences (Denson 2014a: 66-67).

Serials emerged during the period between the two mainstreams of viewer address, that is, roughly between 1909 and $1917,{ }^{2}$ when the transition in film style, exhibition, and technology registered differently with individual spectators (Denson 2014a: 60-61). Beginning with Edison's WHAT HAPPENED TO MARY (1912) and the releases of the serial craze that peaked in 1914 and 1915, serials exploited the possibilities of immersion and attraction, developing their own style and mode of address that existed and thrived until the mid- to late 1940 s. $^{3}$ Serials thus verify Charlie Keil's assertion that in the transitional era 'the erratic process of devising effective storytelling devices often results in an aesthetic beholden to neither the attractions nor the classical phase' (2006: 196). The style and mode of address that film serials formulated borrowed aspects from film's earliest years and from transitional-era strategies of narrative containment. Tracing these elements enables an understanding of their particular and at times peculiar use of repetition, reiteration, and reenactment-elements that especially harken back to turn-of-the-century filmmaking.

Moving beyond Gunning's establishment of the technological apparatus as early film's true 'attraction', Charles Musser appraises the importance of narrative in early films and proposes to consider them 'a cinema of contemplation' and 'a cinema of discernment in which spectators engage in intellectually active processes of comparison and judgment' (2006: 160). The act of contemplation results from an exhibition practice that was common before the turn of the century, when films of about twenty-second length were shown in loops. Viewers observed, for instance, the motions of water running down a waterfall. According to Musser, 'such sustained presentations also encouraged spectators to contemplate and explore the image. As this evidence suggests, one way that early audiences were meant to look at films was not unrelated to the way they were meant to look at

2 The dates demarcating American cinema's transitional era are disputed. I follow Denson in locating the period between 1909-1917, who takes the periodization from Miriam Hansen. For more information on the periodization see Denson 2014a: 72, fn 24.

3 For a historical overview of film serial style and mode of address, see chapter three of this volume. 
paintings' (p. 162). Contemplative film viewing is therefore rooted in an aesthetic appreciation of the moving image and is by no means dependent upon narrative. Musser ascertains that it is indeed the repetitive engagement with a looped moving image that enables the transformation of an initial shock experience or 'attraction' into contemplation (p. 167). A similar effect of repetition informs the weekly rehearsal of a formula in a film serial's episodes, which encourages the viewers to acknowledge its operation. Part of the exclusion of film serials from the 'classical' corpus may indeed be the result of their aesthetic appreciation not being rooted in carefully orchestrated narrative intricacy but in the ready identification of their formula through its weekly rehearsal.

A second mode of engagement with turn-of-the-century film that Musser outlines - the 'cinema of discernment' - similarly results from a rehearsal of film reception. The medium naturally lost its spectacular character as viewers returned to sites of film exhibition and as film viewing became a regular part of urban life in the United States. Taking ThE Black Diamond EXPRESS (Edison, 1896) as an example, Musser explains that such films of onrushing trains were also shown in loops. In order to interest theater patrons who had already seen the film or comparable ones, exhibitors spoke to the audience about the details of the train, for example speed records (2006: 169). This and other practices, such as Edison's filming of sequences from stage performances that encouraged viewers to compare between " the original" and its reproduction' (p. 165), newspaper critics' comparisons of the different roles played by the same actor or of different actors in similar roles, or the comparison of different films depicting trains at full speed, testify that visitors engaged in more intricate viewing activities than simply being stunned (p. 171). Musser reminds us that

Early film spectators performed significant intellectual activity involving comparison, evaluation and judgment—as opposed to (or simultaneously with) either the enraptured spectator passively contemplating a beautiful picture or the "gawker [[...]] held for the moment by curiosity and amazement". [...] Spectators were not just given over to visceral states of astonishment or contemplation: They were critically active.(p. 170 ${ }^{4}$

In its inaugural decade, film thus already offered the delights connected to repetition (of entire shorts), reiteration (of material seen or information generated elsewhere), and reenactment (of scenes from stage plays on film, 
or in remade films). Such practices surface in different ways again and again throughout the history of cinema, not only in film serials but in all aspects of Hollywood's remaking culture. ${ }^{5}$ In film serials, The MiLlion Dollar MYSTERY (Thanhouser, 1914) is a particularly apt example of critical film viewing, as the repetition of a narrative formula and the reiteration of story elements in each episode schooled the devout fan Ida Damon to such an extent that it allowed her to plot the serial's concluding episode. ${ }^{6}$ Musser describes a similar effect of rehearsal or education: 'Returning to the theater to see films for a second time did not necessarily mean the theatergoer was seeking some vestige of astonishment. S/he was now becoming an authority, a sophisticate.' (2006: 171). These are the viewing practices that the film serials of the 1910s, with their formulaic stories and interactive fan cultures, capitalized on. Despite lacking the means to channel and market fan articulation, serials of the 1920 continued to invite comparative viewing and critical reflection through their use of repetition, reiteration, and reenactment.

Serials thus activated formal, narrative, and visual elements in ways that are comparable to early film practices. In other words, serials continued these practices into studio-era film production before and after the transition to sound. Scott Higgins similarly ascertains the relevance of repetition for the sound serial, in an argument that can be extended to silent-era releases:

[C]ompression and repetition work together in the sound serial to forge a cinematic world at once clear, direct and single minded but also frantic, compulsive and focused to the point of obsession. To a certain extent, the long running time and interrupted viewing of a fifteen-chapter serial makes redundancy unavoidable. Each episode must quickly reacquaint returning viewers with characters and their traits, while new viewers need to be brought up to speed. A practical concern for clarity between episodes, however, does not explain the exhaustive repetition within each chapter. (2016: 36$)$

Instead, repetition is a characteristic trait of sound-era serials, which, according to Higgins, offer alternative pleasures to the norms of narrative integration that many scholars and fans associate with American films of the studio era (p. 4). He takes the second episode of FLASH GoRDON (Universal, 1936) as an example, which clarifies Ming the Merciless' (Charles Middleton)

5 'Remaking', in Frank Kelleter's and Kathleen Loock's definition of the term, includes remakes but also sequels, prequels, etc. (Loock 2016).

6 For more details on Ida Damon, see chapter three of this volume. 
plan to marry Dale Arden (Jean Rogers) seven times within fifteen minutes (p. 36; FLASH Gordon, episode two, 'The Tunnel of Terror'). In this episode, the narrative exceeds the amount of repetition that is necessary to keep viewers up to date substantially. With reference to Bordwell, Higgins concedes that films of the classical style also repeat important pieces of information to ensure that viewers can follow the story. However, feature films try to avoid attracting attention to these reinforcements of plot information. Film serials, by contrast, resolutely and unashamedly repeat and reiterate, in the sound serials Higgins describes (pp. 36-37) as well as in silent serials like THE EXPloits of ElAine (Pathe, 1915), as the previous chapter has shown, and certainly in the 1920s. This refusal to hide the fact of narration - that is, to favor presentation over representation - and the less immersed reception of serial spectators are mutually dependent. Higgins describes the relationship of a self-conscious narrative and repetition as follows:

Unlike features, serial narration tends not to recede to the background. The declarative, presentational address of an episode's opening recap and closing cliffhanger makes way for directive and empathic storytelling throughout each chapter. An episode's narrative compression creates a kind of situational intensity; all roads lead to the next crisis. In this narrational environment, repetition pressurizes the problem space; each mention amplifies the deadline's menace. Moreover, repetition and the five-part format help make the act of storytelling visible. Even as a chapter builds tension, viewers can recognize the game at hand and appropriate it to play outside the theater. (pp. 36-37)

Film serials thus employ repetition as a means to insist on and reinforce the intensity of their action plots. They offer prolonged thrill rides across numerous action sequences that are narratively integrated into a chain of episodes but that also self-consciously rehearse numerous ways of reinforcement and reprise. Placed on an imagined scale between the hermeneutic engagement with 'attractions' and its supposedly classical counterpart, film serials indeed appear right at the center: audiences discern ${ }^{8}$ the plot through

7 In Matinee Melodrama, Higgins explains that sound serial episodes are often organized in terms of a five-part structure: they begin with an action sequence, followed by a dialogue sequence, the episode's 'middle action', and another dialogue sequence before the episode's final cliffhanger. Serial episodes are thus organized as 'AbCdE', with capitalized letters standing for action and lower-case letters symbolizing dialogue sequences (2016: 29-35).

8 Quite aptly, Merriam Webster's online dictionary describes 'to discern' as 'to detect with the eyes'. 
its weekly reinforcement and serials present their narratives as though they were attractions, never letting an immersive narrative conceal the fact of its own 'narrated-ness'. This combination of repetition and presentational narration is a prerequisite for the viewers' efforts at operational detection.

A similarly presentational style of narration informs some transitional-era films that are not part of an advertised serial or series. In a study of D.W. Griffith's The LONEDALE OpERATOR (1911), Gunning identifies repetitions at the level of individual shots, often highlighted by means of tinting. These repetitions foreground both the film's editing techniques as well as its narrative structure: 'THE LONEDALE OPERATOR not only is systematic in telling its story but also foregrounds its formal system through repetition, alternation, and rotation' (Gunning 2004: 23). It is this midway between an immersed state of film viewership and a more self-aware experience of the film technology as opaque that serials embrace. Whereas comparable instances also occur within studio-era feature productions, film serials intensify this middle state and turn it into a trademark characteristic.

Film serials' unique approach to storytelling relies on a combination of 'compression and repetition', in Higgins' words. This combination is somewhat paradoxical, as repetitions are the likeliest elements to be removed from a condensed, compact narrative form. Yet the dialectic of self-conscious, presentational narration and the serials' evocation of thrill both depend on repetition. In other words, it is because of repetition that serials both display the fact of narration but nevertheless foster affect. In order to examine the evocation of affective responses, I turn to ideas from the study of another genre that draws on repetition: pornography. In Pornography and Seriality, Sarah Schaschek describes the relevance of recurrence, compression, and formulaic narrative with reference to Susan Sontag:

As a film genre, pornography derives a great portion of its pleasure from the recurrence and predictability of its images, and the meaning of the formulaic structure of the genre cannot be underestimated. "It is the nature of the pornographic imagination to prefer ready-made conventions of character, setting and action", Susan Sontag writes in her 1967 essay on "The Pornographic Imagination". The pornographic universe, she adds, is incomparably economical. Basically, in order to be arousing, "everything must bear upon the erotic situation", even if this means risking a "fatiguing repetitiveness". (Schaschek 2013:2) ${ }^{9}$

9 Schaschek acknowledges that Sontag originally wrote about pornographic literature, which nevertheless bears a similar tendency of formulaic narratives and repetition. 
In other words, pornographic film resorts to established narrative formulae to reduce the story time in favor of an iteration of visual elements that foster a viewer's arousal. Repetition and compression work together to provoke the physical responses that are at the core of the consumption of pornographic films (pp. 40-46). Sontag and Schaschek describe a narrative set-up that resembles film serials in that both forms sidetrack innovation to the benefit of affect. However, whereas the affects of porn culminate in the viewers' arousal, film serials aim to maximize thrills.

Serials thus adopt a narrative strategy that they share with other forms geared towards affect. Linda Williams has prominently identified such forms as 'body genres', which generally exceed the confines of a classical Hollywood film style (1991; cf. Schaschek 2013: 40). Taking porn, horror, and the 'women's film' as examples, Williams stresses that body genre films tend to display 'the spectacle of a body caught in the grip of intense sensation or emotion', and they register in their viewers' bodies respectively with 'sexual pleasure, fear and terror, or overpowering sadness' (L. Williams 1991: 4). Instead of articulating their experiences and feelings with language, the audience's reactions to these films are marked by pre-reflective utterances including the gasps and moans of porn, screams of horror, or the sounds related to crying in melodrama (p. 4). Notably, the narratives of these films are "marked by "lapses" in realism, by "excesses" of spectacle and displays of primal, even infantile emotions, and by narratives that seem circular and repetitive' (p. 3; quoted in Schaschek 2013: 40).

Williams particularly considers melodrama a body genre. At the same time, melodrama is the narrative mode that scholars such as Ben Singer and Scott Higgins have identified as the bedrock of the blood-and-thunder narratives of film serials from The Perils of PAuline (1914) to The Perils OF NYOKA (1942) (Singer 2001; Higgins 2016). In fact, just as film serials benefit from the repository of transitional-era filmmaking, the generic elements and narrative styles of melodrama provide a sourcebook not only for the production of film serials but, as Williams stresses, for most if not all American films. And again, whereas the 'superficial realism' of American features may cloak their nineteenth-century stage heritage (L. Williams 1998: 42), film serials unabashedly employ, reemploy, and stage melodrama especially through the weekly rehearsal of the episode formula. This presentational foregrounding of melodramatic strategy results in a double-edged film experience, which capitalizes on the thrill and pathos of melodrama and simultaneously explicates their creation. This duality results from the fact that serials use repetition in ways that harken back to melodrama's evocation of affect on the one hand, and foster discernment on 
the other (cf. Musser 2006). Serials thus simultaneously demand emotional investment and contemplative reception practices and thereby encourage viewers to conduct operational detection not only of the plot but also of the affordances of the medium and the ways it fosters affect.

In a way, this duality of discernment and affect is inherent in the multiple uses of the term 'embodiment' in film scholarship. Shane Denson points to the difference between its definition in phenomenological studies of human-technology relations and in analyses that counter psychoanalytic or semiotic film theory, such as feminist film scholarship (2014a: 59-6o). The latter take 'embodiment' to refer to non-diegetic film viewers and their awareness of being physically present in the literal space of the theater. This self-aware state of physical embodiment, Denson stresses, is the opposite of what philosophers of phenomenology have described with reference to Don Ihde as 'embodiment relations', in which viewers incorporate a prosthetic technology into their subjectivity. Their attention and intentionality then bypass the technology, which enables their immersion or absorption into a world created on screen. Classical Hollywood film, in other words, increasingly 'privileges phenomenological embodiment relations at the expense of spectators' own embodiment' (Denson 2014a: 6o). Denson concludes that

the wedge of separation introduced by the segregation of filmic and theater spaces was thus lodged not between spectator and film but instead insinuated itself between an abstract spectator and the embodied viewer-between a normative viewing subject on the one hand and the physicality of theater, body, and film technology on the other. (p. 68)

It is this separation that film serials dismantle, as they capitalize upon but also frequently disrupt embodied relationships with film technology. Serials construct an implied viewer who is always cast as physically present in the concrete space of the theater and beyond it. This awareness of viewers as being embodied surfaces pointedly in the connection of serials to magazine and newspaper novels in the 1910 s and comic strips in the 1930s, which extend the narrative into viewers' lives outside of the theater, and in the elaborate lobby and window decorations and other 'ballyhoo' suggested in serial pressbooks. Instead of immersing viewers in the film experience and bypassing their awareness of the cinematic apparatus, serials branch out into the viewers' non-filmic environment. Through its paratexts and ballyhoo, a serial's narrative begins to share a life-world with its viewers, 
and the cinema and the eras' multiple other media outlets are a part of that environment. ${ }^{10}$

In part, the serials' deviance from a more readily immersive model of spectatorship results from their division into episodes that reference each other and the broader context of the series or serial. The break between installments encourages an awareness of the cinematic mediation of the film as well as a critical reflection about the ongoing, unresolved narrative. A spectator's momentarily immersed state of reception is forcefully broken up with the presentation of an episode's ending or, more abruptly, with its cliffhanger. A large question mark on the screen or a 'see the next episode of $\mathrm{xxx}$ at this theater next week' not only reminds viewers of next week's episode but quite consciously points to the 'mediated-ness' of every episode-stressing that spectators themselves cannot control when to see the following episode. The previous state of immersion, however, itself existed only for a brief instant because the episode's beginning likely failed to engulf its viewers, due to its introduction of characters and re-caps of previous plots. ${ }^{11}$ Instead of drawing viewers in, serials reach out to them, addressing them in their respective theater seats and even beyond, in their daily lives between a serial's individual installments. Thus, whereas a physical response such as a gasp in a thrilling situation might have disrupted the immersed state of an idealized film spectator, the serial viewer never became that absorbed in the first place. In this way, serials circumvent the separation of the filmic and the theater space and forfeit a clear distinction of physical embodiment and an embodied, or prosthetic, relation to the cinematic technology.

Serials reiterate a similar formula each weekly episode to an extent that directs attention towards both the formula and its repetitiousness. In this context, viewers may also reflect upon a serial's means of evoking affect, as thrills also occur on a regularized schedule and follow recurring patterns. The experience of watching a film serial is thus decidedly 'machinic': viewers watch the 'storytelling engine' at work; they witness its ever-repeated motion, which is itself an end rather than a means towards the delayed resolution of the story. In this sense, the viewers' activities

10 See chapter three of this volume. Whereas features similarly use ballyhoo, the extra-filmic life-world they create usually exists for a shorter period of time and does not unfold alongside the viewers' weekly personal routines.

11 We can understand the 'what happened last week' blurb at the beginning of episodes of television series as a way to 'bracket' the re-cap with its presentational address and thus further an immersive film experience afterwards. Film serials of the 1920s, however, often integrated the re-cap instead of framing it as extraneous to the episode. 
of detection or discernment are indeed operational: viewers are invited to reflect upon the operation of the cinematic serial machine and upon their own engagement with its operation. As episodes follow one after the other, serials accumulate convoluted arrangements of characters, plots, schemes, and images. The result is a continuous negotiation of narrative explanation and occasional attempts at containment versus the rapid frenzy characterizing modernity at large. As Ruth Mayer has shown in her reading of THE TRAIL OF THE OctopUs (1919), the serial references the synoptic view and understanding of classical detectives such as Sherlock Holmes, but it shows the non-transferability of this set-up to the context of American serial cinema. These serials are hopelessly convoluted and they 'explode[] the confines of linear narration'. The task of the viewer thus resembles the job of the now defunct diegetic detective, who was 'relentlessly striving to turn chaos into order, processing random events of violence or loss as interlinked "cases" that needed to be assessed, correlated, and resolved' (Mayer 2017: 23, 25). Serials invite such acts of detection, although without enabling actual possibilities of resolution, by encouraging viewers to crossreference several instances across multiple episodes, outside of the serials' weekly scheduling. As the following case studies will show, serials repeat, reiterate, and reenact instances to establish relations between narrative and visual elements outside of the serial's release schedule and narrative chronology. Serials encourage a comparison of such instances, fostering discernment as well as affect, both of which combine into the pleasurable and thrilling activity of operational detection. The following case studies will be presented out of chronological order, beginning with THE HOPE DiAmOND Mystery (1921) and OFFICER 444 (1926), which both structure their presentational address similarly, followed by THE POWER GOD (1925), which also encourages operational detection but without a directly proposed narrative agenda. Instead, the serial correlates scenes in a way that later occurs more pointedly in the 1937 sound serial RADIO PATROL.

\section{The Two Serial Structures of The Hope Diamond Mystery}

The Hope Diamond Mystery (1921) combines four different storylines in four settings, each of which centers around a valuable mineral called the Hope diamond. The serial's initial scenes are set in Britain, where Lord Francis Hale (Captain C. Clayton) unsuccessfully attempts to buy the Hope diamond from an American merchant (William Marion) for his wife. The setting then switches to sixteenth-century Burma for an interlude that provides 
the backstory of the French merchant Travanier (George Chesebro) and his theft of the diamond from an ancient religious idol. The eighth episode relocates to the United States in the 1920s, where a villain in yellowface (Harry Carter) attempts to steal the diamond from its owner, the American merchant from the early episodes set in Britain. The serial's final episodes are set on a remote island, where the chief villain, who has dropped his mock-Asian attire, once again endeavors to steal the diamond - this time by hypnotizing the merchant's young secretary Mary (Grace Darmond) and placing her under his spell. The four stories and settings differ in terms of their visual aesthetics, which range from showing a strong similarity to other film serials of the 1910 in the early scenes, to the elaborate acting in the Burmese setting, to a 1920 s realism of the island setting.

Across its fifteen episodes, The Hope Diamond Mystery thus skips through four stories, with four sets of characters, whose interrelation results from the casting of the same actors in comparable roles in each story. Additionally, the stories connect through their shared myth of the Hope diamond, which in each story sparks greed and adulterous love relations. Juxtaposing these four stories, the serial manifests the immorality apparent in each of them as a direct effect of the diamond on its owners and on its pursuers. Conversely, the myth of the Hope diamond only comes into being because the viewers compare and contrast the serial's multiple storylines.

The serial itself points to the added value of a comparative reading in its third episode ('The Forged Note'). In a sequence set in early twentiethcentury Britain, the American merchant lends the diamond to Lord Hale as its prospective buyer, before being placed in 'suspended animation' by a group of villains. ${ }^{12}$ Knowing the merchant to be out of the way, Hales' servant Dakar (Boris Karloff) and the criminal Nang Fu both consecutively attempt to obtain the diamond by presenting Hale with a forged note from the merchant. However, the second trickster makes his attempt while the initial one is still in the house and thus spoils both of their schemes. The repeated attempt alerts Hale, who compares the handwriting on both notes and thereby detects the trick. Through close-ups of the notes, the viewers examine the notes and perform a task of comparison that resembles their efforts to correlate the serial's four story sections. Like Hale abstracted the trickery from its repeated application, viewers can detect the spell of the

12 Suspended animation was a means to temporarily render the villain powerless, which was also used at the end of THE Exploits of ElAINE, probably to justify the villain's return in THE New Exploits of Elaine. In The Hope Diamond Mystery, suspended animation is used to put the character of the American merchant on hold until his return numerous episodes later. 
Hope diamond from the threefold reenactment of its effects. Such a reading, however, is based on a perception of the serial's structure that differs from its release in fifteen consecutive episodes. In other words, THE HopE DiAMOND MYSTERY combines two strategies of sequencing: on the one hand, the serial adheres to the multi-episode structure that was common for film serials at the time, replete with repeated plot and character introductions and cliffhangers endings, which I will refer to as formulaic seriality. On the other hand, the serial assembles its four sequences in a montage that is reminiscent of D.W. Griffith's InTOLERANCE (1916). ${ }^{13}$ I will refer to this latter organizational structure, in which individual stories connect with reference to a shared theme such as 'intolerance' or a myth such as that of the Hope diamond, as thematic seriality.

Rudmer Canjels stresses the serial organization of INTOLERANCE, a film that also assembles four stories in different settings and endows individual passages with a moment of heightened emotionality or suspense before switching diegetic locations. According to Canjels, the film is organized according to 'a form of seriality that is focused on the repetition of the same idea and disrupts the linear narrative flow'. The disruption between its passages is 'naturalized through use of theme', but it nevertheless 'bursts through the story in quite obtrusive ways' (2011: 8). The connection between the passages results from the comparative perception of the audience instead of from an editing technique that smoothens the transition from one passage to another. Griffith acknowledged this fact when he stated that 'the greatest value of the picture will be in its suggestive value to the audience, in the manner in which it will force it to create and work out the idea that I am trying to get over' (quoted in Hansen 1994: 137). THE Hope DiAmonD MYsTERY similarly invites its viewers to abstract an overall theme from a correlation of the four stories. Nevertheless, the results of the viewers' comparisons differ: in Griffith's film, they know they will encounter four different stories, each of which portrays one instance of intolerant behavior. The Hope Diamond Mystery, by contrast, does not give away its trope as easily. Instead of naming the theme invoked in each story-which could be greed, jealousy, or in the broadest sense immorality - the serial presents the Hope diamond as a symbol. The stone stands in for the theme, which the serial urges us to detect.

Such comparison is also encouraged by the framing of the four stories as retrospectively narrated by May Yohe. Yohe was an American singer and

13 In fact, later features offer similar montages, for example The ThreE Ages (1923), Buster Keaton's parody of InTOLERANCE, or Michael Curtiz' NOAH'S ARK (1928). 
vaudeville actress who had been married to the British Lord Francis Hope (who inspired the serial's Lord Hale) and had owned the diamond until about twenty years before the release of The Hope Diamond Mystery. She took part in writing and promoting the serial (Fowler 2002: 244), and she appears in the beginning of its initial episode, which depicts her at a desk, composing her own story and that of the diamond. ${ }^{14}$ Later episodes end with title cards signed by Yohe, in which she urges viewers to return for the next installment. ${ }^{15}$ The serial thus connects its four stories not only by means of the diamond as both a recurring (though hardly ever visible) prop and a symbol for a larger theme, but also by suggesting that these stories were intentionally assembled and arranged by a narrative authority. The references to Yohe in the serial on the one hand foster comparison, on the other hand they point beyond the serial's diegesis to the larger discourse surrounding the Hope diamond.

In the early twentieth century, a number of myths and stories about the diamond circulated and were picked up by newspapers, which similarly cast the diamond as a demonic stone that elicits its respective owners' immoral tendencies. As a note in the Exhibitor's Herald from 26 February 1921 reminds the audiences: "The Hope diamond is undoubtedly the most sinister jewel in the history of the world. It has an authentic history dating back to 1,400 years and it has a story of disaster and misfortune' (Exhibitor's Herald, 1921). Viewers thus not only compare the serial's four stories, but they may additionally contrast them with their own previous knowledge of the myth. The serialized reception experience, which extends the engagement with the story over several weeks, opens up timeframes between the installments during which the cross-reference to extra-filmic texts can take shape. In the intervals between episodes, viewers can reflect on and communally discuss both the serial's relation to the Hope diamond myth and the reverberations between its four story elements. Disruption and correlation thus interact in complex ways, as the serial's larger theme both results from disruption and connects the disrupted narrative parts, but also adds to the dismembering of a possible narrative integrity by enforcing a larger, extra-cinematic contextualization. The serial thus invites a mode of reading that rewards various efforts of comparison and cross-reference that explode the confines of both a narrative chronology and the filmic text.

14 Today, the Smithsonian Institution owns the Hope diamond, which is part of the National Gem and Mineral collection at the National Natural History Museum in Washington, D.C.

15 Yohe acts as a nondiegetic narrator, whereas 'her part' in the serial, re-named 'Lady Hale' in the British setting, is played by the actress Ethel Shannon. 
Canjels similarly extends his argument about the seriality of INTOLERANCE to the segmentation of film serial narratives into multiple episodes. An individual episode's repetition of the previous week's cliffhanger, he argues, is comparable to the feature film's larger theme in so far as they both serve to reduce narrative disruption-especially so as Canjels writes about serials that, in contrast to The Hope Diamond Mystery, do not feature an overall myth or theme. In his words, 'a serial narrative does not function independently; its jarring beginning and ending were naturalized through its use of a repetitive episodic pattern that was known to the audience' (2011: 9). Indeed, for viewers who were familiar with the cliffhanger structure, the sudden ending of an episode most likely failed to cause a stir. Nevertheless, the way The Hope Diamond Mystery re-introduces its narrative premise at the beginning of individual episodes grants an insight into the serial's politics of disruption and continuation. Like most serials across the decades, THE Hope DiAmOND Mystery's plot recaps limit themselves to the narrative information that is necessary to understand the situation that it picks up from the previous installment's ending. After the setting relocates to Burma about halfway through episode four, for instance, the ensuing episode's recap only introduces audiences to the Burma story - withholding the fact that the ensuing story of the original diamond theft is told retrospectively by the mysterious servant Dakar ('The Jewel of Sita'). Instead of providing narrative information to familiarize viewers with the story, the recap serves to recreate a state of emotional investment. Rather than reminding us of what happened last week, the serial reminds us of what we felt by the end of the previous installment. Repetition thus helps to reduce both a narrative and an emotional disruption from episode to episode, whereas the serial's multiple other forms of reprise foster comparison outside of such a scheduled chronology, as the following passages will illustrate.

THE HOPE DIAMOND MYSTERY arranges its four stories and settings in clusters. Apart from a few minutes set in Burma in the initial episode, the serial's first episodes are set in London. In episode four, the setting switches to pseudo-historical Burma. A later cluster of episodes takes place in the contemporaneous United States, before the story finally relocates to a remote island. This grouping of episodes according to their setting enables the serial to retain a linear seriality between individual episodes, whereas the comparative readings that effect the thematic correlation between clusters of episodes establish broadly overarching relations and repercussions. The comparison of the different stories and the detection of the overall theme thus remains a privilege of loyal viewers who return to the cinemas for 
most of the episodes. ${ }^{16}$ These latter viewers notice that the story circles around itself; that each cluster enacts very similar incidents. Later episodes in fact reenact scenes from earlier ones and thereby foster and reward the audiences' comparative efforts. Nevertheless, the reenactment of a sequence that already occurred earlier necessarily implies that the resolution of a particular narrative instance is clear from the get-go. As a result, the viewers' efforts at detection coincide with an aesthetics of the operational, where the viewing experience hinges on the unfolding of process rather than its eventual resolution. The pleasurable film experience then results from the activity and process of detection rather than from any consequential insight.

In the eighth-episode cliffhanger and in episode nine, for example, which are set in the contemporaneous United States, the villain Nang Fu (Harry Carter) enters the estate of the American merchant and approaches his secretary Mary (Grace Darmond) with the implied intent of either rape or murder, or both. In the nick of time, the criminologist John (George Chesebro) breaks the door and rescues her ('Yellow Whisperings', 'The Evil Eye'). This sequence reenacts an instance from the preceding episode, where, in sixteenth-century Burma, the wealthy townsman Ghung behaves similarly towards his fiancée by arrangement, the much younger Bibi. In this instance, it is the French merchant Travanier who kicks in the door and saves the fearful woman (episode 7 , 'Flames of Despair'). Both of these instances conjure up a similar narrative paradigm, racist implication, and visual imagery, the correlation of which is fostered through identical actors taking the parts of Bibi/Mary, Ghung/Nang Fu, and Travanier/John. Although the narrative motivations differ - the story set in the United States, for instance, lacks the previous episode's arranged marriage - the latter scene takes up its predecessor's character constellation, situations, and emotional states.

In both scenes, the Hope diamond is only tangentially related to the portrayed action. Nevertheless, it is greed that in sixteenth-century Burma just as in the twentieth-century US co-occurs with self-ascribed male superiority and the ensuing victimization of the female lead. It is the recurrence of the situation that connects greed and immorality to the diamond that lends the serial its title and its weenie. In addition to thus reinforcing the overall theme, the reenactment of such micro-plotlines addresses the repetitiousness of serial narratives and its relative autonomy

16 A similar grouping of episodes took place with the re-release of Griffith's INTOLERANCE in 1919, when its four thematic elements were grouped and the Babylonian and the modern age story were released independently as two films called THE FALL OF BABYLON and THE MOTHER AND THE LAW (Canjels 2011: 22). 
of stock plots from setting and mise-en-scène. THE HoPE DiAmOND MYstery admits to cinema's more general tendency to reenact generic storylines in varying settings, on which film serials in particular capitalize and which they lay bare by means of exaggeration. The eighth episode's reenactment of a previously shown scene thus combines a foregrounding of narrative operationality - as the familiarity redirects attention from the scene's outcome to its staging — with a similarly operational presentation of filmic storytelling practices.

It is thus no coincidence that the serial exhibits repetition through the reenactment of the motif of the racialized rape threat, which recurs throughout the history of silent-era filmmaking and well beyond. In the earlier instance, the Burmese Ghung threatens Bibi, who is also from Burma but has been introduced as 'the fairest' woman in town (episode 7 , 'Flames of Despair'). In the second instance, a malefactor who resembles a prototypical Chinese supervillain ${ }^{17}$ approaches the white secretary Mary. Whereas the most common invocations of the cross-racial rape threat concern African American men and white women, films of the 1910s and afterwards conjure up the same stereotype in relation to Native American, Chinese American, or Mexican American characters (Projansky 2001: 40). More generally, serials and features repeatedly cast white males as the saviors of white women in the hands of non-Caucasians. ${ }^{18}$ The repeated adoption of the motif in The Hope Diamond Mystery can thus-maybe even in defense of the serial-be read as pointing to cinema's frequent reinforcement of racial stereotypes and motifs.

A similar notion of reenactment informs the climactic ending of the serial's final episode, which takes up an instance from the seventh episode. In a scene that marks the end of the Burmese interlude, Ghung is stabbed by a dancer (Carmen Phillips) who is jealous of his sexual interest in Bibi ('Flames of Despair'). The final episode then relocates the scene to the remote island: now, Sidney Atherton (who earlier posed as Nang Fu) has hypnotized Mary to both render her sexually obedient and obtain the diamond from her. Jealously stalking the two, Atherton's wife Wanda eventually stabs her husband to death on the beach (episode 15, 'An Island of Destiny'). This

17 Of which the archetype is Fu Manchu (Mayer 2014). The fact that the villain Nang Fu in this serial is introduced as a white man dressing as an Asian-despite possibly addressing the practice to let white actors play Asian characters - is a necessary means to enable the final episodes set on an island. Nang Fu there appears in his undisguised form as Sidney Atherton, who hypnotizes Mary and courts her. The images of the two in close embrace might have been considered offensive at the time if Atherton had been Asian.

18 The Adventures of Kathlyn, for instance, as Sabine Haenni has shown. 


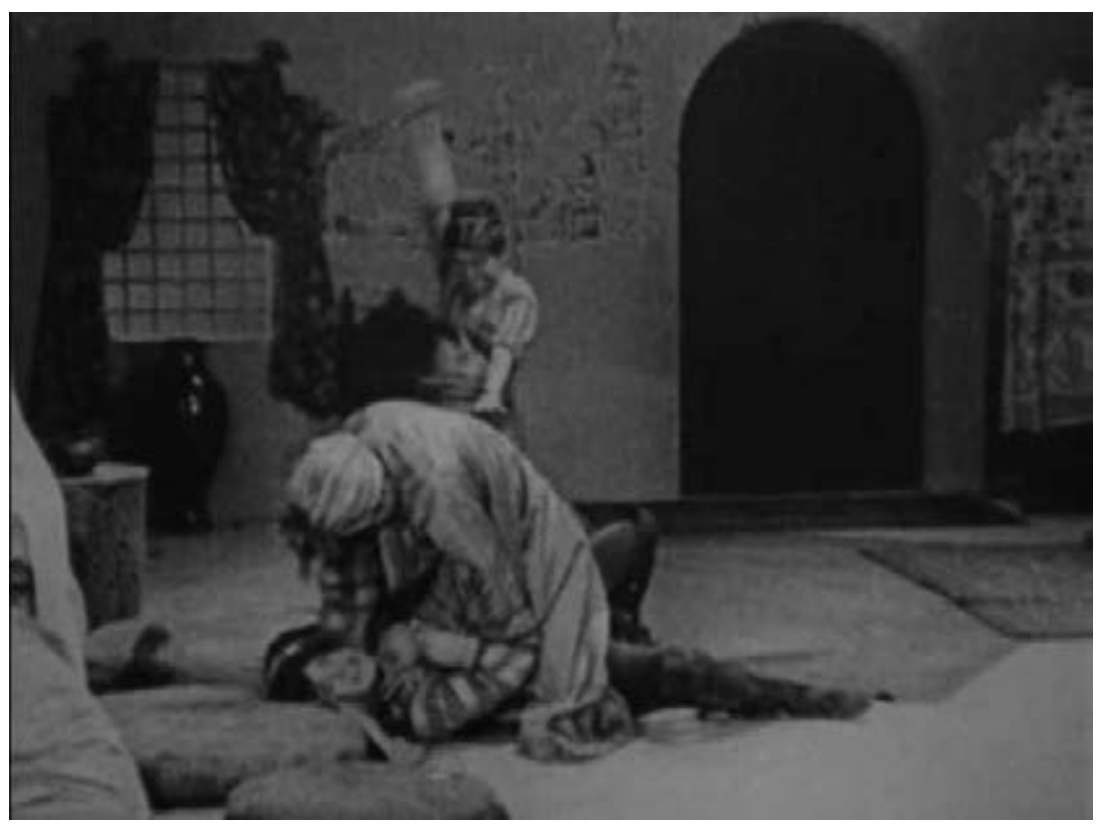

21. The dancer stabs Ghung while he is fighting Travanier (The Hope Diamond Mystery, episode 7, 'Flames of Despair').

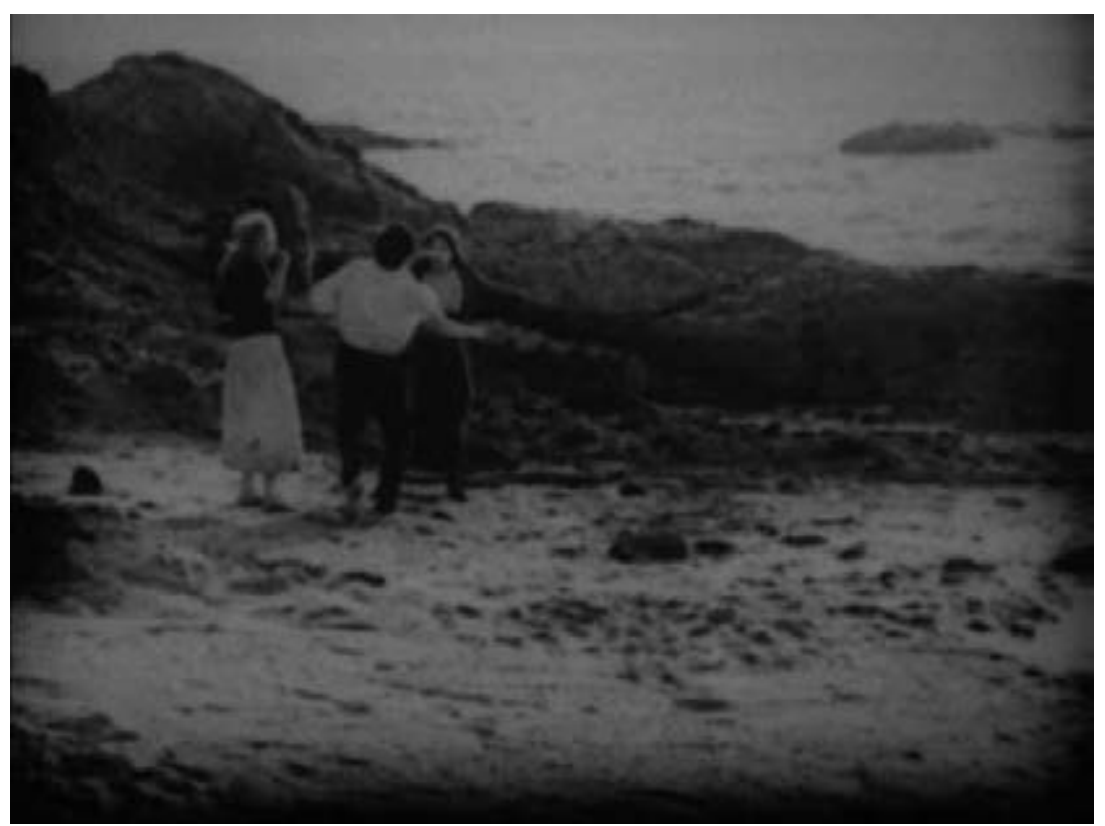

22. Wanda stabs her husband Atherton while he courts Mary (The Hope Diamond Mystery, episode 15, 'An Island of Destiny'). 
scene again awards attentive viewing, this time by correlating an instance with one that occurred eight weeks earlier in the serial's run. Moreover, in killing its main villain twice, the serial addresses the commonality of a villain's death at the end of silent-era films.

Considered in concert, the reenactments in The Hope DiAmond MrsTERY harken back to a racialized staging of violent hyper-masculinity and female victimization ${ }^{19}$ that seems to be concluded at the end of episode seven. Overall, the serial enacts the rape threat trope three times, activating the stereotype with a different ethnicity each time. In such instances, the serial capitalizes on stereotypes and narrative formula as a means to reduce narrative exposition in favor of affect in a way that resembles pornographic film styles. Reenactment, just as other forms of reprise like repetition or reiteration, heightens emotional investment through the excessive invocation of affective filmic moments. THE Hope DiAMOND MYSTERY is blood-and-thunder melodrama, but its way of heightening pathos through narrative circularity resembles porn's strategy of provoking arousal more than any of the more 'classical' filmic strategies. The melodramatic mode, particularly as it is employed in Hollywood filmmaking, rests on a 'dialectic of pathos and action', in which pathos results from a prolongation of time, through extended displays of virtuous suffering and tableau shots, among other things (L. Williams 1998: 42, 59; cf. Kelleter, Mayer, \& Krah 2007). Serials adapt the conventions of melodrama to their condensed, action-oriented format to an extent that induces Singer to argue that serials 'present moral polarization without pathos' (2001: 55). ${ }^{20}$ Taking The Perils of PAuline (1914) and The HazArds OF HELEN (1914-1917) as examples, he maintains that serials and action films more generally do victimize their protagonists, but only in order to show their 'bravery and resilience', and specifically not to evoke pity for a protagonist's selfless self-sacrifice in the face of moral injustice. Serials, he argues, neglect pathos and focus on action instead (pp. 55-56). However,

19 Sarah Projansky identifies female vulnerability as a stock element of American film: 'in such films with drugged, hypnotized, orphaned, and silenced women, innocence makes women vulnerable to rape; other films transform previously independent women into vulnerable women by subjecting them to rape or sexual violence' (2001: 32 ).

20 Although not neglecting pathos entirely, Higgins assigns sound serials a similar tendency towards action: 'If melodrama, as Linda Williams proposes, depends on the "dialectic of pathos and action", then sound serials are clearly unbalanced. Suffering, the violation of innocence, and the recognition of loss are, for Williams, inextricably linked with the thrill of action through which heroes struggle to regain and defend virtue. Sound serials, and cliffhangers in particular, rehearse the threat of physical suffering defeated by daring action, but they divorce the thrill from pathetic emotion' (2016: 64). 
The Hope Diamond Mystery is overly melodramatic — not necessarily in comparison to features, but definitely when contrasted with other silent-era serials. Both serials and features evoke pathos, but they make use of different strategies to do so. Whereas features often create pathos through displays of virtue, individual instances in the serial quickly skip over portrayals of suffering. Across numerous episodes, however, the serial stresses pathos through reenactment.

The apparent neglect of a portrayal of pathos appears markedly in the first adaption of the rape threat narrative in episode seven, set in Burma. When Bibi is threatened with sexual assault by Ghung-her husband in an arranged marriage to which Bibi disagreed-medium close-ups of her face in anguish are outnumbered by shots portraying a parallel plotline of her approaching rescuer. Whereas the prolongation of climactic rescue sequences through parallel editing is endemic to the melodramatic mode, this particular scene offers a plethora of developments that co-occur with Bibi's predicament. These include one of Ghung's co-conspirator's attempt to steal back the bride price from Bibi's father, her lover Travanier's break-in into the house and engagement in a fight over the bride price, the death of Bibi's father, and Travanier's prolonged ascension of the stairs, before he finally busts through the door to save Bibi (episode 7 , 'Flames of Despair'). Bibi's plight recedes into the background in favor of an accumulation of action, and the scene's pathos results from viewer response rather than being implemented on screen. The serial thus prolongs its protagonist's time of suffering, but it limits the visual display of her sobbing. More generally, once a character is in peril, film serials prolong suffering either by extending narrative time through parallel editing, or by relegating the rescue to the following episode. Either strategy prevents viewers from visually witnessing the suffering that we nevertheless know of. ${ }^{21}$ Whereas each individual of the serial's many climactic instances quickly skips over moments of pathos, the reenactments in THE HoPe DiAMOND MYsTERY reinforce female victimization and they heighten pathos by provoking pity for characters in peril. Pathos thus results from a circular reinforcement of affect. Similar to the plots of pornographic films, the evocation of affect works despite the viewers' knowledge of the narrative outcome. In fact, the anticipation of future narrative developments and affective states itself seems to heighten pathos. Therefore, in summary, reenactment helps implement the pathos that threatens to get lost in the wake of the serial's overall stressing of action.

21 Nevertheless, some serials display more pathos than others. For sound-era examples, see Higgins 2016: 64-65. 
Corresponding to the presentational mode of storytelling of film serials, the reenacted instances heighten pathos while simultaneously laying bare the narrative strategies underneath. Through reenactment, the serial admits to its own recycling of stock situations, and it addresses the formulaic character of melodrama more generally. The interchangeable actualization of racial stereotypes in the multiple reenactments exhibit the variability of melodrama's prototype villains. As Williams reminds us, 'melodrama presents characters who embody psychic roles organized in Manichean conflicts between good and evil' (1998: 77). THE Hope DiAmOnd Mystery presents evil interchangeably as Caucasian, Burmese, or in yellowface.

The serial thus alerts viewers to the fact that 'the features of the villain are not fixed; one era's swarthy cape-enveloped villain is another era's smiling villain' (p. 77). The Hope Diamond Mystery not only invites us to enjoy melodrama and its affects, but it also encourages us to watch melodrama work. Because of its reenactments, the serial defies a contradistinction of immersion and a self-reflexive foregrounding of melodramatic strategy. Its corresponding insistence that within formulaic narratives, anything can happen again is underlined by the fact that none of the rescues or stabbings effectively end the narrative. Instead, the humble servant cum mysterious character Dakar obtains the diamond in the end and takes it back to its original position as the decoration of a religious idol (episode 15, 'An Island of Destiny'). The serial thus 'begins, and wants to end, in a space of innocence' (p. 65), in tune with the melodramatic mode.

THE Hope DiAmond Mystery, I argue, offers a particular mode of engagement in which reenactment is a key to the understanding of an underlying narrative scheme but also a means to heighten pathos while predominantly visualizing action. Just as Lord Hale understands Dakar's and Nang Fu's scheme when both try an identical trick on him, the spectators can understand the impact of the Hope diamond on its respective owners and their contemporaries only through reenactment. The viewers engage in efforts of comparison that allow them to identify the spell of the diamond, while reenactment feeds into their emotional investment at the same time. This is how THE HoPE DiAmond MYSTERY invites acts of operational detection that are neither fully immersed nor based upon alienation. As the following pages will show, OFFICER 444 similarly references and reiterates an overarching theme, but the serial employs reenactment to an extent that lays bare the materiality of film production. 


\section{'Fix Your Hat!': OfFICER 444's Ridiculous Repetitions}

OFFICER $444^{22}$ is a 1926 police procedural that fuses its crime plot with comedy and slapstick. Ben Wilson both produced it and took on the leading role, co-starring with Neva Gerber. At the time, both of them were established stars of the film serial business. Wilson had appeared in Wно WILl MARRY MARY? in 1913, the sequel to what is considered the first American film serial: What HAPPENED to MARY. In 1917, he and Gerber acted together in THE VoICE ON THE Wire (Universal), followed by at least three more ${ }^{23}$ jointly acted serials before the release of THE POWER GOD (Davis, 1925), which I will examine more closely later in this chapter, and OFFICER 444.

At first sight, Officer 444 barely resembles The Hope Diamond MysTERY. Whereas the latter capitalizes on the affects of melodrama, OfFICER 444 explores the affective potential of comedy. Nevertheless, both serials employ comparable strategies to evoke affect, they each require the viewers' efforts to compare and contemplate, and they invite them to engage in operational detection. The following pages will detail the strategies by which OFFICER 444 both engages its audiences in an affective film experience and encourages operational detection. As I will show, both of these aspects of the film experience are based upon repetition, reiteration, and reenactment.

The ten chapters of OFFICER 444 interconnect not only through weekly cliffhangers, but because of a thematic framing that is established with reference to a star figure in ways that resemble May Yohe's appearance as a storyteller in The Hope DiAmond Mystery. Whereas in the latter case, Yohe's audience address underlines the myth of the diamond, Officer 444 proclaims a self-ascribed documentary agenda of portraying modern, effective police work. A number of episodes begin with a title card reminding viewers that the police often protect scientific marvels from sinister crooks. A following title card then announces that

this serial's purpose is to present for public knowledge the "inside" facts in such a struggle, showing the machinery of the police in full swing against

22 Parts of my argument about OFFICER 444 were developed further in a paper written collaboratively with Ruth Mayer, 'Modernity Management: 1920s Cinema, Mass Culture and the Film Serial' (Brasch \& Mayer 2016).

23 The Mystery Ship (Universal, 1917), The Trail of the Octopus (Lynch, 1919), and The SCREAming Shadow (Hallmark, 1920). Gerber also starred in the final serial that Wilson directed, The Voice from the Sky (G.Y.B./ Hollywood Pictures, 1930), which is likely to have been the first serial with fully synchronized sound. 
a sinister gang seeking the secret of an amazing chemical discovery, which, in the true scientist's hand, means Life-in the crook's Death...

(e.g. episode 1, 'The Flying Squadron')

The serial emphasizes this didactic function through cameo appearances of August Vollmer, who at the time was the chief of police in Berkeley, California, where the serial is set. The serial positions Vollmer at the switchboards of the police machinery: Numerous episodes show him at his desk, sorting through mail, answering the phone, or discussing recent developments in the pursuit of the dubious criminal organization 'the ring' with members of the police force. In contrast to May Yohe in The Hope Diamond Mystery, Vollmer is not an extradiegetic narrator, but his cameo appearances are firmly integrated into the serial's narrative world. Nevertheless, his appearances do conjure up and reiterate a larger discourse. Although the serial's description of him as 'one of the world's foremost criminologists' may be somewhat hyperbolic, Vollmer was known in the United States for heading the movement of 'scientific policing', which aimed to enhance the credibility of police methods such as the tracing of fingerprints. He introduced new approaches to his Berkeley police squad, known as the 'college cops' (Cole 2001: 200). OFFICER 444 thus places its story within a larger context of modern scientific police work, into which it promises its viewers a surplus of insight. Instead of explaining police procedures, the serial demonstrates them to its viewers, allowing them to watch investigation and pursuit in action, or 'in full swing'. By repeating this introductory announcement at the beginning of its first six episodes, OfFICER 444 stresses its presentational address and simultaneously foregrounds narrative organization and storytelling as a process.

This agenda of demonstrating efficiently organized police work seems counterintuitive for a serial that presents anything but a carefully orchestrated narrative. The machinery of the police has gone haywire-it meanders frantically and follows no discernible logic. Neither the protagonist cop Officer 444 (Ben Wilson) nor the Flying Squadron of policemen, of which he is a part, ever devise successful stratagems. Neither do their opponents, the members of 'the ring'. The policemen and the criminals rather pursue each other in weekly back-and-forth movements, without any actual investigative work. Instead of a plot development and forward momentum, OFFICER 444 presents a convoluted chaos in which characters frantically run about and provoke endless numbers of fistfights. The serial's witless investigative journalist and comic sidekick Snoopy (Harry McDonald) summarizes this lack of narrative organization when he tells a gas station clerk in the second 
episode: 'Gimme a pint of gas —I've got a lot of running around to do!' ('Human Rats'). ${ }^{24}$

The serial compensates for its rather loose narrative organization by adhering to the strict formal structure of two-reel episodes and their weekly character introductions, chase sequences, and cliffhangers. The order of episodes is prescribed by the matching of cliffhangers and their resolutions rather than by narrative progress or development. However, the convolution and chaos make sense in connection to another discursive context that the serial references: comedy and slapstick. 'Officer 444' appears to have been the name of a vaudeville sketch that was played in various cities in the $1910{ }^{25}$ In the same decade, Essanay released the comedy short A Mistaken CALLING that features a policeman called Officer 444 (Moving Picture World). At a visual level, the serial bears a strong resemblance to the Keystone Kops, which were immensely popular in the 1910s. Whenever the Flying Squadron rushes to a site of crime or follows a lead, plenty of cops pile into one convertible car. The shots of the Flying Squadron in a car, and also later ones of the policemen in their headquarters, are near direct visual copies of scenes from Keystone's slapstick shorts. The serial seems to take seriously the similarly alliterated names of Vollmer's 'college cops' and the 'Keystone Kops' of comedy films. OfFICER 444 not only capitalizes on the humorous effect of such references, but it reenacts them with ironic twists that add another layer of signification. The cops' repeated rushes to the rescue in overcrowded patrol cars, for instance, culminate early on in an instance in which Snoopy falls off the car at a turn (episode 3 , 'Trapped'). This scene transforms the Keystone-Kop reference into an instance of outbidding ${ }^{26}$ that reenacts earlier instances within OFFICER 444 rather than reiterating the reference to other non-serial films.

The serial picks up on aspects of the successful silent-era culture of episodic slapstick shorts, but it additionally champions the weekly serial

24 This sentence initially seems to constitute a moment of 'foreshadowing' in Bordwell's sense; however, rather than pointing to a future element in the 'cause-effect logic of the film', Snoopy addresses the absence of such a logic in the serial (Bordwell et. al. 1985:44).

25 Variety lists 'Officer 444' on the vaudeville bill at Cohen's in Poughkeepsie, NY, in the week of 4January 1915 (Variety, 1915). The New-York Tribune lists it in the vaudeville program at Loew's American in 1918 (New-York Tribune, 1918), and it similarly appears in Variety that year (Variety, 1918).

26 Frank Kelleter and Andreas Jahn-Sudmann have identified outbidding as the tendency of serial narratives to surpass earlier episodes or other series, in their case particularly twentyfirst-century television series, in terms of sexual explicitness or violence. Chapter four of this volume offers a more detailed take on outbidding in The Exploits of Elaine. 


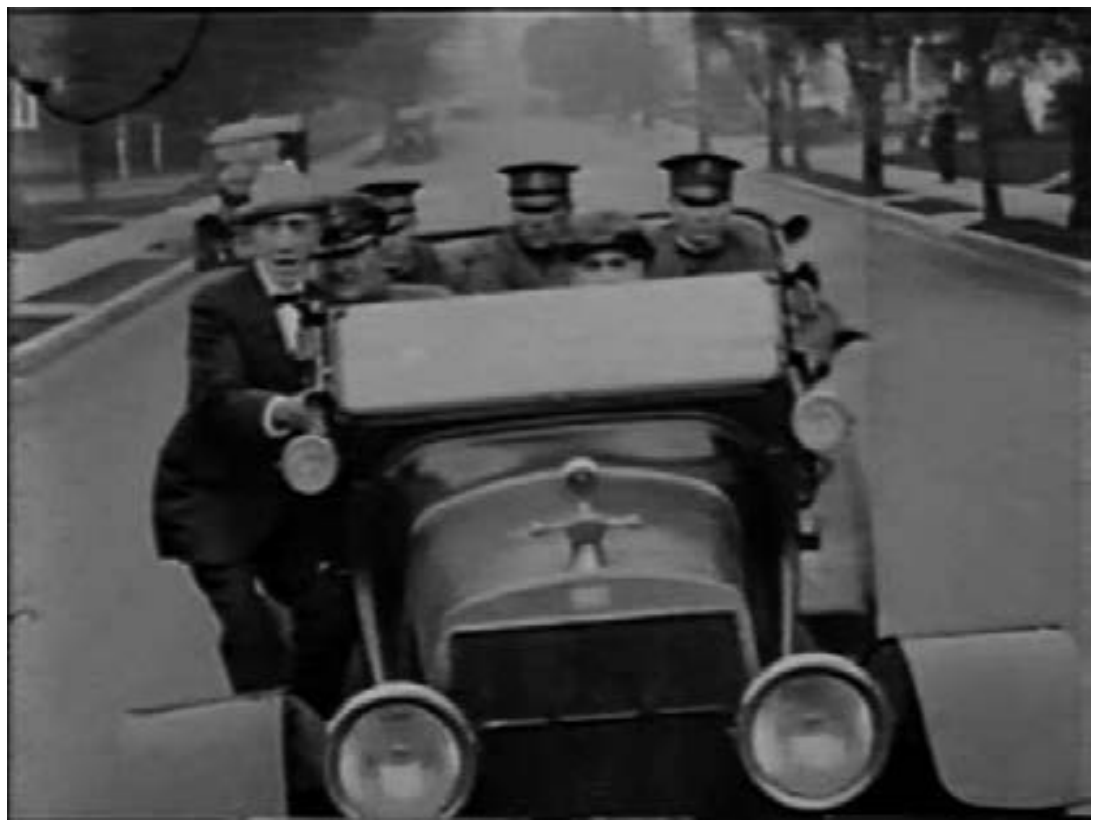

23. The Flying Squadron rushes to the crime scene in OfFICER 444, episode 3, 'Trapped' (released by Grapevine Video).

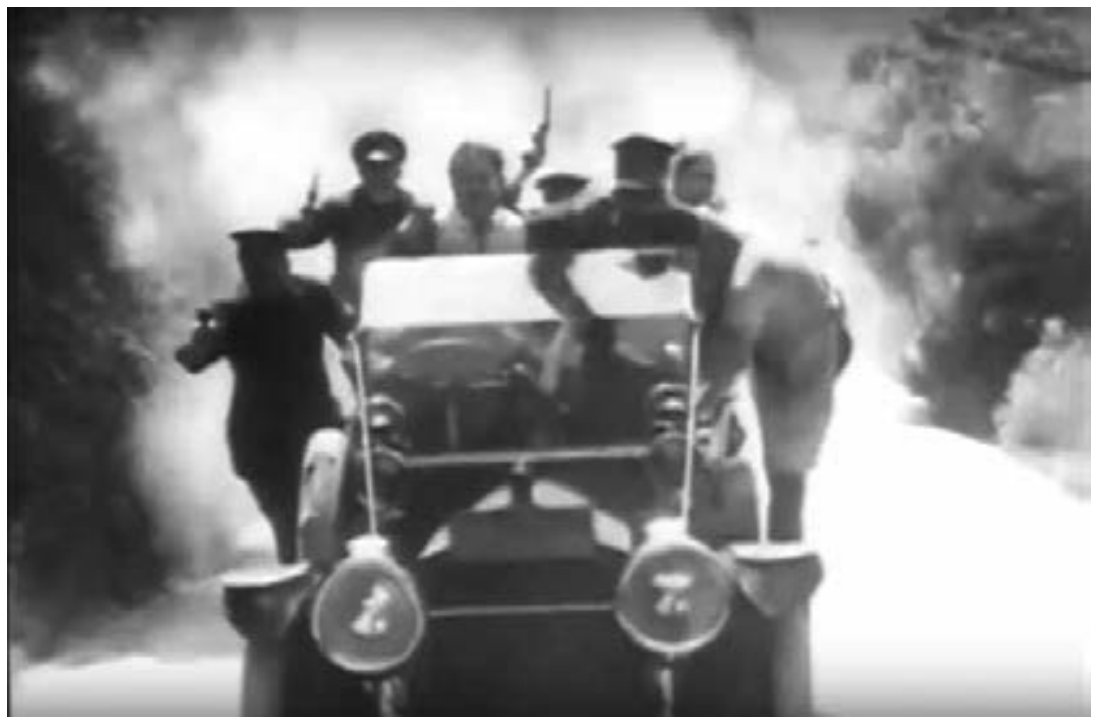

24. Film still of the Keystone Kops from A Hash House Fraud (Keystone, 1915). 
format. Another joke that is reenacted across multiple episodes concerns the police officers' uniforms: 'Fix your hat!' emerges as the most frequently repeated sentence in the serial. The cops even agree on a light signal for it (episode 2, 'Human Rats'). By the serial's third episode, the sentence has become so familiar that an instance in which officer Patrick Casey (Jack Mower) reminds the journalist to adjust his cap works without the corresponding intertitle ('Trapped'). In fact, 'fix your hat!' can be seen to describe the serial's paradox more generally: while the investigation and pursuit result in complete chaos, the Flying Squadron should at least keep a respectable appearance. By repeating its agenda to portray potent police work at the beginning of its episodes, OFFICER 444 similarly and figuratively 'fixes its hat'.

Despite its unique slapstick influence, OFFICER 444 shares the narrative formulae and storytelling conventions of numerous film serials from the time. Its generic framing narrative begins with the death of a genius inventor and the loss of a secret chemical formula. The Flying Squadron, the journalist Snoopy, and 444's love interest, the emergency hospital nurse Gloria (Neva Gerber), attempt to recover the formula and shatter the criminal organization 'the ring'. The ring, in turn, is led by a prototypical masked, hunchbacked, limping villain called 'the frog', the ruthlessly scheming femme fatale 'the vulture' (Ruth Royce), and the sinister physician Dr. Blakley (Al Furguson), who is part of a similarly untrustworthy organization of international (mad) scientists. Based on these parameters, the serial constructs weekly episodes that are connected in adherence to the organizational conventions of filmserial storytelling. Every episode repeats the cliffhanger from the preceding one, introduces the main characters, and lists relevant cornerstones of the narrative. OFFICER 444 thus reminds us over and over again that the 'frog' and his 'ring' are evil and that the scientific formula needs to be rescued from their hands. These repetitions introduce first-time viewers to the narrative, and they reinstate the affective tone for loyal patrons. Whereas cliffhanger endings use the storytelling and editing techniques of the melodramatic mode to build affect over several minutes, the subsequent episode must recall the same affective state in a few seconds, which it does by combining a repetition of the final frames of the cliffhanger with title cards that explain the main agents and plotlines.

Perhaps more than other serials, OFFICER 444 revisits the same cinematic spaces in Chinatown, the underground sewage system, Dr. Blakley's medical practice, the police station, and the emergency hospital. At the same time, the serial self-consciously reflects its repetitiousness in humorous ways. Such reflections occur in short instances within individual episodes. Episode four, 
for instance, comments on the serial's frequent fistfights when, in a scene set in the police station, Officer 444 and his colleague Casey practice their fighting skills ('Gassed'). The same episode also employs reenactment in a way that self-reflexively exposes narrative formula. In contrast to THE HoPE DiAMOND MYSTERY, OFFICER 444 does not relocate its reenacted scenes to another time and place; instead, similar or identical incidents happen multiple times to the same characters. In episode four, the protagonist policeman disguises himself as 'the frog' in an attempt to find Gloria, who was kidnapped in Chinatown. The criminals immediately recognize the imposter and 444 can forward the disguise to a naïve passerby, who consequently receives a beating. Later in the episode, 444 poses as Dr. Blakley to save Gloria from brain-altering medical treatment. However, the frog enters the operating room and exclaims that 'this man is not Dr. Blakley!', thus inaugurating the obligatory fight scene ('Gassed'). In addition to ridiculing the policeman's dilettante acts of imposture, the episode draws attention to the formulaic masquerades of serial villains. Just as THE Hope DiAmOND MYstery informs us early on that Nang Fu is a white man posing as a prototype Asian villain, OFFICER 444 introduces the frog as 'one of those creatures who so often stir our sympathies, when in reality his supposed affliction is but a false cloak of crime!', exposing the stereotypical appearance of its master criminal (episode 1, 'The Flying Squadron'). Whereas this earlier sequence exposes the frog's appearance as masquerade, the exchange of disguises in episode four elucidate that prototypical serial villains are not only stock characters within the melodramatic mode but also placeholders, empty shells that are simple to don, discard, exchange, and replace. When taking up the villain's disguise, 444 thus in a way undermines the serial formula, assuming and passing on its stock positions. OFFICER 444 thereby exposes the transformation of the melodramatic mode into the formulaic grid of film serials.

444's infiltration of the villainous gang not only foregrounds formula, but it simultaneously disrupts melodrama's parallel-edited rescue 'in the nick of time'. When the policeman posing as Dr. Blakley stands before Gloria's operating table, surrounded by members of the ring, he clandestinely spills the essential liquid in order to save her from harm. Nevertheless, the scene is intercut with shots of the Flying Squadron's rush to the rescue (episode 4, 'Gassed'). In this scene, melodrama's classic narrative and editing technique successfully amplifies suspense despite the fact that 444 is on the scene and Gloria is safe already. Although as film viewers we are expecting the rescue 'in the nick of time' and often take it for granted (L. Williams 1998: 72), serials face the dilemma that a rescue in the nick of time is foreseeably inevitable. Viewers can rest assured that their heroes will survive simply because 
further episodes are scheduled at the cinema. ${ }^{27}$ OFFICER 444 structurally aligns itself with the audience in its admittance of this fact and, when we see the medical utensils approaching Gloria's face, the joke is on the Flying Squadron rushing to the rescue nevertheless. Whereas melodrama traditionally evokes pity by granting its viewers more knowledge than its characters, OFFICER 444 uses the same surplus of knowledge for comedy. The serial thus employs filmic strategies of the melodramatic mode to evoke affect, but instead of encouraging pathetic (or sympathetic) emotions, OFFICER 444 hijacks melodrama for a joke.

This approach to melodrama again reiterates elements of Keystone's comedy cop films of the previous decade. According to Rob King, the Keystone Kops first appeared in ThE MAN NeXt DooR (Keystone, 1913), which was also the first comedy that ridiculed the melodramatic convention of crosscutting shots of characters in peril with the approach of their rescuers. In the film, the cops' clumsy behavior rules out any efficient rush to the rescue and thus counteracts the temporal dramaturgy of parallel editing (King 2009: 44-46). This strategy became a standard in Keystone's comedies, as, according to King, 'of at least fifteen extant prints ending with a paralleledited rescue released in 1913, eleven feature Keystone's roughhouse cops as the would-be rescuers' (p. 45). Like OfFICER 444 a decade later, Keystone's comedies parody melodrama's 'moral iconography' while simultaneously relying on 'the genre's formal capacities for suspense' (p. 6o). The serial adopts a double-edged use of melodrama that King describes not as blunt satire but as 'pastiche, as a form of mimicry lacking parody's satiric edge: the melodramatic mode is mobilized less as a target of critique or distanced irony than through a comic self-consciousness that exploits and relies upon melodrama's framework of thrilling effects' (p. 61). The policemen of OFFICER 444's Flying Squadron are less clumsy than their transitional-era predecessors, and the joke of the fourth-episode rescue action results from Gloria's safety instead of from temporal retardation. What the serial retains is the self-conscious use of cinematic techniques to evoke affect. The result is an integration of self-reflexivity and immersion, that is, of the possibilities of a viewer's physical sense of being embodied, literally, in the cinema and his or her simultaneous prosthetic, embodied relation with the apparatus that enables film perception.

Despite all the similarities between OfFICER 444 and the Keystone Kop films, the serial's self-ascribed agenda of portraying efficient police work

27 Scott Higgins analyzes how THE LONE RANGER successfully incorporates a possible 'too late' in the sound era (2016: 67-68). 
is at odds with its references to the shorts. The Keystone company stylized itself as a place of free play and experimentation, where making slapstick comedies was just as much fun as watching them (King 2009: 35-36). Yet Keystone also was a pioneer when it came to the Taylorization of the film production process, with departmentalized work units and continuity scripts that helped to monitor the work progress (p. 33). It was this combination of a 'carnivalesque affirmation of inefficiency and riotous playfulness' and an industrialized, rationalized production process that led a writer for Motion Picture News in 1914 to call Keystone a 'fun factory' (p. 37). OfFICER 444, and serials more generally, practiced the Taylorist division of labor to excess. Budgets were small and production time was limited, and the frequent returns to previous locations bear as much witness to this as the use of repeated or library footage. By referencing August Vollmer and the repeated promise to document efficiency, OFFICER 444 stresses its own mode of production. However, individual episodes hardly offer meaningful narrative progress and the serial's aim is, mostly, the suspension of its denouement. In a way, OFFICER 444 seems to juxtapose efficiency and slapstick in ways that enable a view at a fundamental paradox of film serials and American cinema more generally: in their reliance on repetition and reiteration, the most economically efficient productions are narratively speaking the least efficient ones. Rather than having been produced in one, OFFICER 444 itself is a 'fun factory': a narrative entertainment machine that chugs along and yet repeats the same task, which is both efficient yet endlessly prolonged.

OFFICER 444 lays bare this seemingly endless prolongation in a series of reenacted sequences that eventually dismantle the narrative project and expose the material base of filmmaking. In episodes three ('Rats'), four ('Gassed'), and five ('Missing'), co-conspirators of the frog intercept sensible information from Officer 444 and the journalist Snoopy when they call police headquarters from a shop near Dr. Blakley's medical practice. Each time around, a spying store employee warns the ring of the approaching police. In the first instance, Officer 444 arrives at the medical practice by himself and is being knocked unconscious by one of the frog's henchmen. The second time, the entire Flying Squadron appears but finds the medical practice empty - devoid of both people and furniture. Before the squadron's third excursion to Blakley's, the police captain expresses his frustration with Snoopy in an exclamation that applies similarly to the repetitious nature of police work and of the serial's plot: 'If you're kidding me this time, I'll have you shot before sunrise' (episode 4, 'Gassed'). Nonetheless, the Flying Squadron speeds to Blakley's practice once more. Having again been warned, the members of the criminal organization convert the medical practice into 


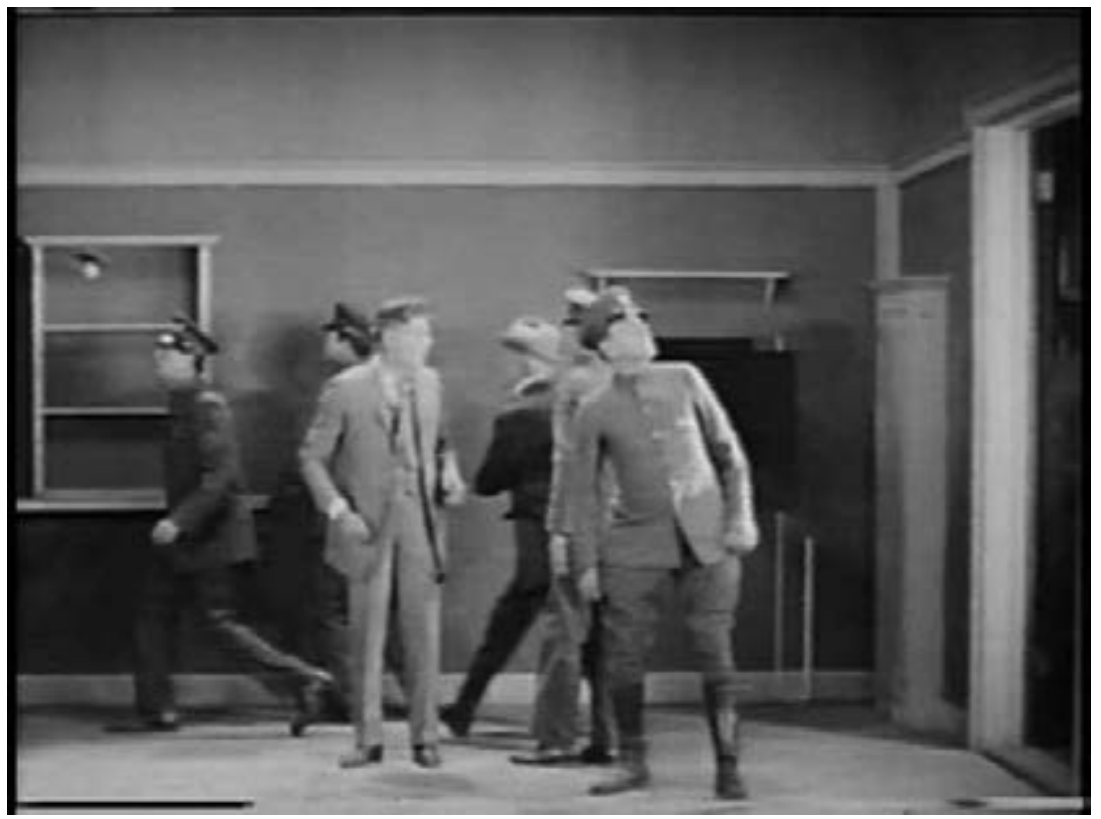

25. The Flying Squadron arrives to find the medical practice empty (OfFICER 444, episode 4, 'Gassed,' released by Grapevine Video).

a shop for work overalls (episode 5, 'Missing'). Viewers thus literally watch the actors set the scene for the ensuing action, which involves the arrival of the policemen and the destruction of the medical practice/store/set during the ensuing mass brawl.

More bluntly than The ExPLOITS OF ElAine, as shown in the previous chapter, OFFICER 444 at this point engages in what Andreas Jahn-Sudmann and Frank Kelleter call 'outbidding': a process of surpassing, in which each new iteration of the scenario aims to outdo its predecessor. The authors argue that series and serials - in their case, twenty-first-century television series - constantly aim to outbid each other and their own previous episodes and thus often threaten to become, for instance, overly violent or sexually explicit. In order to release the pressure thus built up and to avoid alienating audiences, serials at times include 'signals of irony' (Jahn-Sudmann \& Kelleter 2012: 214). Maybe more than counteracting possible moral reservations, OFFICER 444 resorts to irony through reenactment to steal the thunder of viewers who may criticize the serial for its overly repetitious organization. When the Flying Squadron shreds the fake shop and its backrooms to pieces, cops and villains seem to be fighting over the control of the material film set. Having won the physical argument, the policemen take the scattered 
furniture along, returning the set to a stage of emptiness. The narrative turns into farce and meanwhile exposes the materiality of film production and its serial appropriation of space, as sets become exchangeable in an instant. By emptying the set, the policemen make room for new stories, despite the fact that the serial will nevertheless continue to reiterate and reenact the same formulaic abductions, rescue sequences, and brawls.

OFFICER 444 thus allows us to trace an infinite web of repetitions, reiterations, and reenactments at a formal level, both narratively and visually, and extraneous to this particular serial. On the one hand, repetition serves to heighten the affective engagement with the serial, especially across the breaks between episodes. On the other hand, reenacted elements foreground the storytelling process and urge viewers to draw the connections. The serial thus encourages operational detection, that is, an analysis of the processes of storytelling as it unfolds and meanders while simultaneously taking part in an affectively stimulating film experience. And whereas OFFICER 444 exposes the material basis of film production when it destroys the set, THE POWER GoD transposes a similar self-reflexivity to the level of lighting, as the following passages illustrate.

\section{Tesla Tests and Thunderstorms in THE POWER GoD}

A year prior to the release of OfFICER 444, Ben Wilson and Neva Gerber appeared together in THE Power GoD (Davis, 1925). The serial's fifteen episodes combine a thrilling, pathos-laden story with comic interludes that pick up racial puns from the vaudeville tradition. Instead of being part of a team, the protagonist Jim (Ben Wilson) is a lone fighter, the assistant of an inventor who is murdered early on in the serial. ${ }^{28}$ Throughout the episodes, Jim alternatingly protects or aims to retrieve the inventor's daughter Aileen (Neva Gerber) and the genius innovation, a machine that draws electric power from air. His opponents are a group of power magnates who aim to steal and suppress the invention to secure their own oil operations and a criminal gang that was originally hired by the businessmen but then decided it would profit more from stealing the invention for itself.

Like the earlier examples of The Hope DiAmond Mystery and OfFicer 444, THE POWER GoD capitalizes on reiteration and reenactment to heighten emotional investment and to reinforce central issues of its plot. As the

28 The inventor in fact dies in a fistfight. Whereas both fistfights and murder occur often in serials, death as the result of a fistfight is rare. 
following passages will show, later episodes remind us of or reenact earlier scenes and invite us to compare and contrast instances in the serial in a non-linear fashion. However, the serial lacks reference to an outside figure or 'star' to evoke extra-textual discourses and to ensure a connection between the episodes other than that of their weekly chronology. Instead, THE PowER GoD establishes electricity as its central concern, which informs both the serial's narrative and its visuals.

Before his death in the first episode, the inventor tests the power engine and demonstrates it to Jim and Aileen, and simultaneously to the film audience. The episode visualizes the engine's successful operation with Tesla coil special effects and sparks that emit from the mechanism ('The Ring of Fate'). The scene is set in the dark, and the reflection of flashes of light on Jim's and Aileen's faces create an aesthetic that is reminiscent of the famous 'creation scene' in FrankensteIn (1931) or of what Ruth Mayer describes as 'the markedly aestheticized enactment of electricity' in THE MASK OF Fu MANCHU (1932) (2014: 69) - all of which showcase Tesla coil effects. ${ }^{29}$ THE Power GoD's inclusion of Tesla technology corresponds to its 'weenie' invention, because the idea of drawing electricity from air is comparable to Nikola Tesla's real-life attempts at the wireless transmission of electricity. Tesla terminated these attempts in 1917, when his famous Wardenclyffe tower that served to issue an electrical current was demolished. Using Tesla coil to illustrate the functioning of its power engine, THE POWER GoD reinstates an electric utopia that Tesla himself abandoned less than a decade earlier.

The envisioning of such a utopian ideal is well-grounded in the lived experience of audiences in the 1920s, when urban and suburban residential communities were electrified while most rural areas lacked access to power lines (Nye 1990:141). While the dissemination of electricity that had begun in the 1880s neared its end in the mid-1920s (Whissel 2008:118), the decade also marked electricity's transition towards corporate consolidation. Previously, private enterprises had ensured the power supply of downtown

29 The use of Tesla coil for cinematic special effects is typically attributed to special effects wizard Kenneth Strickfaden, who used Tesla coils for example in Frankenstein (1931) and THE MASK OF FU MANCHU (1932) but also in sound serials such as The VANishing SHAdow (1934), The Lost City (1935), and The Amazing Exploits of the Clutching Hand (1936). Harry Goldman argues that Strickfaden was likely to be influenced by film serials that staged Tesla coil special effects, including The Romance of Elaine (1915), THe Black Box (1915), Wolves of Kultur (1918), The Great Radium Mystery (1919), Hidden Dangers (1920), and The Power GoD, which Goldman dates to 1926 (Goldman 2005: 78). In 1919, Picture-Play Magazine explained that 'Nikola Tesla is a moving-picture enthusiast, and especially dotes on serials. For the last three years, it seems, he has seen every episode of nearly every serial produced' (Picture-Play Magazine). 
businesses and wealthy homes, municipal plants had provided electricity for streetlights, and companies that ran streetcars had brought power to amusement parks and to communities along their routes. In the 1920 s and 1930s, by contrast, the supply of electricity was centralized in increasingly influential businesses (Nye 1990: 26). This shift provoked debates over public versus privatized electric supply and centralized versus widely diffused power generation (p. 138). Whereas electrification eventually played out according to the ideals of corporate capitalism, large parts of the population, according to David Nye, 'still harbored utopian expectations for a better, electrified tomorrow which would include all citizens, and most engineers retained some version of the dream of technocratic rationality' (p. 184).

THE Power GOD engages in this discussion by introducing a fictional, functioning apparatus that could make electricity universally accessible and by staging a negotiation of its advantages and downsides. In its first episode, the serial highlights the revolutionary potential of a decentralized power supply that would threaten the rule of 'fuel and power barons', who 'tremble on their thrones' ('The Ring of Fate'). In its explanation that the master villain Dore (Al Ernest Garcia) aims to become the 'Power God', the serial equates a centralized electric supply with religious monotheism and political monarchy. The power engine, by contrast, embodies democracy and/or a self-subsistent lifestyle. The serial's juxtaposition of utopian dreams and capitalist intervention is played out particularly in relation to Jim's mother (Catherine Kent), who occupies a rural home 'across the lake' and is dependent on gas lighting (episode 3 , 'The Living Dead'). Whereas this scene pinpoints a precarious lack of electricity, other instances in the serial stress the advantages of a truly mobile power supply for transportation, leisure, and business. When Jim and Aileen escape the criminals in a speedboat, for instance, they attach the power engine to the boat's motor and outpace their pursuers (episodes 9, 'Perilous Waters', and 10, 'The Bridge of Doom'). THE POWER GOD advertises such a decentralized, wireless power supply until the victory of the protagonists in the final episodes. However, in a curious narrative twist, Jim and Aileen destroy the power engine to avoid jeopardizing the jobs of people employed in the businesses that provide electricity (episode 15, 'The Wages of Sin'). The final episode thus aligns the serial's plot with the increasingly consolidated corporate model and simultaneously returns the story to the state of its initial beginnings. Corresponding to the narrative closure strategies of melodrama, episode fifteen reinstates the original equilibrium that was disrupted not by the inventor's death in episode one but rather by the demonstration of the power engine, which animated the story's central conflict. 
Although the Tesla coil effects in THe Power GoD are admittedly less spectacular than those of early 1930 features, their use nevertheless conveys something similar about the impact of the visualization of electricity on the cinema screen. Writing extensively about James Whale's FrankensteIn, Shane Denson points out the presentational qualities of the moment in which Dr. Frankenstein successfully animates the monster. In this 'creation scene', the animation of the monster stands in for the equally electric animation of moving pictures. According to Denson, 'Frankenstein himself drives the point home: “Quite a good scene, isn't it?” What follows is an extended allegorization of cinematic creation' (2014a: 87$) \cdot{ }^{30}$ While the creation scene in Frankenstein brings forth a monster, THE POWER GOD's engine yields no visible product other than sparks of light. These sparks serve as visual illustrations of electricity as the serial's central yet intangible concern. And because such sparks are fleeting, the serial time and again reiterates and reenacts the visualization of its central concern.

The serial revisits the initial testing of the power engine twice: it reiterates its original testing in episode six ('House of Peril'), and it reenacts the test later on in the house of Jim's mother (episode 12, 'The Storm's Lash'). The sixth episode marks the ending of a sequence of negotiations of memory and repetition that informs the preceding four episodes. In the cliffhanger ending of the first episode, Aileen Sturgess is involved in a car accident with the villain Dore, after which she suffers from a loss of memory. Both she and the villain are brought to a nearby doctor who assumes they are a married couple. When the doctor explains that 'her trouble is amnesia. Sometimes memory is restored by repetition of an important event in the patient's life', Dore seizes an opportunity to become legal heir of the power engine and suggests that the two of them should 'repeat' their wedding (episode 2, 'Trapped'). He thus tricks Aileen into marriage, and attentive viewers spend the following episodes hoping for an actual repetition of a previous event in her life that could restore her memory. At the same time, the instance addresses the ritualization of events as, within the logic of the serial, there is no difference between repetition or originality when it comes to the wedding ritual, which either way establishes the reality of marriage. And again, the identification of the wedding as original rather than reenactment depends on Aileen's memory, the return of which similarly depends upon reenactment.

The serial postpones the moment of relief to the sixth episode, and in the meantime embarks on an emotional tour de force that begins with Aileen's 
placement in a sanatorium, which, we learn, serves as a storage facility for unwanted family members. In these episodes, THE PowER GOD outbids the victimization of the previous decade's serial queens, but it also calls to mind nineteenth-century discourses of female hysteria (cf. Singer 2001). In an attempt to rescue her, Jim is imprisoned in the sanatorium's holding cells - a situation that further adds to the dark tone of the story. At the same time, Jim's appearance offers narrative means for comic relief. The fourth-episode cliffhanger, for example, features the shadow of a gunman on the prison walls who, an episode later, reveals himself to be a caretaker pretend-playing the guitar on a broom (episode 4 , 'Black Shadow' and episode 5, 'The Death Chamber'). However, despite lightening the mood of the story, this instance also pressurizes the problem of Jim's confinement as viewers realize that the protagonist is held captive in a psychiatric ward run by the insane. Another attempt at comic relief suffers from unusual morbidity and capitalizes on stock racist jokes. When the inmate of a neighboring cell passes away, Jim dons the corpse's burial shroud, is carried away in the casket and placed on a truck by two hired African American helpers. What follows is a routine of racist sketches in which Jim first scares off the helpers by leaving the coffin in the white shroud and posing as a ghost, and then takes their place in blackface (episode 5 , 'The Death Chamber'). The serial thus aims to counter its dark tone in comic relief that nevertheless fails to lighten the mood. The result is an affective joyride in which plot developments seem to be continuous reactions to previous scenes rather than carefully planned events. The plot is propelled along and meanders, and immediate threats and problems obfuscate the broader quest to secure and patent the power engine.

The return to the engine test in the sixth episode, that is, to the 'creation scene' that animated the conflict in the first place, effects a narrative reboot that reins in the convoluted plot momentarily. Instead of framing the original engine test as a flashback, the episode - in line with the presentist storytelling of film serials more generally (see chapter three)—re-presences the earlier instance, it reiterates the serial's broader concern because of its relevance to the present scene. In fact, Jim's and Aileen's return to her father's house, in which they hope that 'scenes familiar to her since her childhood may restore her memory', becomes a practical pretense for a compilation of relevant plot information from previous episodes (episode 6, 'House of Peril'). Instead of providing the full backstory, however, the serial practices the reduction of information, rebooting the story while discarding unnecessary elements of the convoluted narrative. The return of Aileen's memory is then effected not through childhood memories-as film-serial characters typically lack personal histories—but rather through 
the discovery of a newspaper article about the power engine that she read with Jim and her father in the initial episode. She re-reads the newspaper clipping and the serial repeats a shot — framed as her memory — of the three characters reading the newspaper in episode one. This visual repetition and diegetic reiteration are what allow her to remember. The scene thus effects a narrative reboot, after which the serial abandons its pendulum motion between thrill and comedy in favor of the former.

A real reenactment of the power engine test follows another six episodes later, in 'The Storm's Lash' (episode 12). Jim and Aileen get a hold of a duplicate of the power engine and test it in another 'creation scene' with Tesla coil effects, which, in accordance with the serial's utopian vision, takes place in Jim's mother's rural home. This reenactment similarly initiates a narrative reboot: being in possession of both a prototype engine and paper plans to build it, Jim and Aileen rush to the patent bureau in Washington. This second engine test resembles the initial one not only visually but also in terms of its contextualization within the narrative. The first episode's cliffhanger, which caused Aileen's accident and memory loss, was set during a thunderstorm. In the twelfth episode, the engine test is similarly followed by 'a sudden electrical storm' in the area. The serial thus reinforces the connection of electricity and air, which to an extent explains and justifies the serial's mysterious energy generator. ${ }^{31}$

Aesthetically, the thunderstorms chime in with the demonstrations of the power engines. Both tests are set in the dark, as Jim turns off the laboratory lights in the initial test and extinguishes the gaslight in his mother's parlor in the later instance. As a consequence, the electric sparks issued from the Tesla coil are the only remaining sources of light and their flashes reflect on the faces of the surrounding characters. Between these flickers, the cinema screen switches to a complete black, causing the audiences' perception of the film to take place in the form of individual flashes of lightning or lighting. Their faces similarly reflect the light issuing from the film screen, and the dark theater space lights up and turns dark in synchronization with the film. These instances foreground the projector as a light source in the film theater as well as electricity as film's animating force. Moreover, the dark frames between the flashes make apparent the viewers' dependency on film's electric source. THE PowER GoD engages its viewers in a game of 'now you see it, now you don't' - a mode of viewing that similarly applies to serial viewing practices more generally.

31 Incidentally, the 'creation scene' in Whale's FrANKENSTEIN (1931) equally coincides with, and is narratively framed as dependent upon, an occurring thunderstorm. 
In film scholarship, the phrase 'Now you see it, now you don't' has been prominently employed by Tom Gunning to describe the temporality of the cinema of attractions. In his words, the sentence 'stresses both the spectator awareness of the act of seeing and the punctual succession of instants' (1993: 11). Taking a 1904 Biograph short depicting a tracking shot through a New York subway tunnel as an example, Gunning explains that the change of lit and dark spaces and the flickering caused by passing support beams in the tunnel results in a visual patterning that seems to constantly renew itself. A similar temporality informs other films of the attractions type, particularly those of onrushing trains or the 'peeping tom' shorts. All of these films are organized less in a narrative that links the past and the present and enables viewers to anticipate a narrative future, and more in brief, 'sudden bursts of presence' (p. 6). In contrast to the classical spectator's competent reading of narrative, Gunning argues, 'the viewer of the cinema of attractions plays a very different game of presence/absence, one strongly lacking predictability or a sense of mastery' (p. 11).

Subjected to the alternating presence and absence of serial episodes at their local cinemas, serial viewers always give up part of their sense of mastery in favor of the serialized film experience. THE PowER GoD foregrounds this loss of competence when it stages flickers of lightning in dark settings and thereby attributes mastery to the electric source of the power engine and to the film projector. At the same time, the serial works to counter this loss of control by stressing its diegetic character's control of light. The serial's episodes show an almost disturbing number of instances in which characters switch lights and lamps on and off. Almost every light is diegetically integrated and can be regulated by the characters peopling the screen. The serial thus grants its characters a kind of agency that the serial's viewers do not have. This way, the serial protagonists emerge as 'Power Gods' within the narrative. In the meantime, the serial counters the viewer's powerless position by granting them more information than its diegetic characters, in keeping with the melodramatic mode. Throughout the first six episodes, for example, viewers are aware that the villain Dore already has a wife. Other examples of the viewers' privileged position include episodes nine and ten, when Jim and Aileen escape with the power engine in a speed boat and viewers already know that the villain's henchmen are waiting for them on the shore ('Perilous Waters', 'The Bridge of Doom'). Or two episodes later, when Aileen is forced to sign over ownership of the power engine to the crook in exchange for Jim's freedom, who we know has escaped already (episode 11, 'Treachery'). The serial thus narratively 
counteracts the fact that the logic of 'now you see it, now you don't' reminds viewers of their lack of control over the image.

Whereas Gunning locates the dialectic of presence and absence at the core of the cinema of attractions, Denson considers a similar structure pivotal to the immersive experience of classical Hollywood:

The concept of suture emphasizes the spectator's integration, primarily by means of continuity editing, into the diegetic world of film, the assumption of a subject-position in that world most literally realized in the "identification" with absent characters in shot/reverse-shots and pointof-view. Thus, a presumed presence-absence dialectic, which explains the "as-if" nature of (classical) cinema's reality illusion, is established as the heart of cinematic subjectivity. The underlying (and largely suppressed) interface of body and technology, on the other hand, is a matter of pure presence, a "positivist" phenomenon (in a Deleuzo-Guattarian sense). It is at this level of subjectivity that a pre-personal shock-effect occurs: it is here that cinema's technologies "cut" into the lived body, and only against this background that a sublimating suture can be effected. (2014: 92-93)

Thus, the shot/reverse-shots that effect suture and an immersive film experience are based upon a similar dialectic of presence and absence as the one informing early-twentieth-century attractions, in that both hinge on the alternation of 'now you see it, now you don't'. According to Denson, cinema's reality illusion — and with it the presence/absence-strategy — can only come into being because film viewers enter an embodied relationship with the technologies that enable film perception. Viewers enter an uninterrupted relationship with the screen and projector and, to oversimplify it, forget the presence of these technologies and concentrate on cinema's reality illusion instead. The thunderstorms and Tesla coil effects in THE PowER GoD transpose the dialectic of presence and absence from an abstracted visual level, in which viewers experience film technology as transparent, back to the image itself, and with it to the material apparatus of film. To employ Denson's terminology, 'the underlying interface of body and technology' is specifically not a 'matter of pure presence' anymore. Confronting its viewers with split-seconds of black images, THE POWER GoD employs a radicalized version of the presence/absence dialectic, which defies suture and instead points to the projection lights as cinema's enabling technology. Thus negating an idealized notion of suture, THE POWER GoD can freely play with the dialectic of presence and absence, because the serial form does not, or cannot, achieve suture in the first place, due to the dialectic 
of presence and absence of their weekly release pattern and exhibition schedule. Like lightning, each episode bursts into presence. The in-mediasres beginning of most serial episodes does indeed appear as a sudden flash. Cliffhanger endings typically show their heroes and heroines jumping from an airplane, drowning in a lake, riding a car off a cliff, or being trapped in a complicated death contraption. Ensuing episodes then repeat the climactic final seconds and continue with the cliffhanger's resolution in a way that lets the break seem almost unintentional, with the repetition making up for the unfortunate interruption. Every week, viewers find their story just where it ended before the lights went on.

The use of Tesla coil in THE POWER GOD effects an aestheticized staging of electricity in a memorable moment that not only initiates the serial's central conflict and concern but also serves as an anchoring point for the narrative. However, the flickering lights of the effect and the ensuing thunderstorm highlight the disruptive bursts of presence and absence. Whereas the test of the power engine stages electricity in a contained, controlled environment, the following thunderstorm foregrounds the chaotic, disruptive character of electricity. The reenactment of the engine test in episode twelve is thus to a certain extent Janus-faced: it provides a narrative reboot, a secure position from which to reorganize the ensuing plotlines, but it is right away framed within the uncontrollable flicker of natural but nevertheless electric lightning. The return to the iconic moment is already subverted by its own aesthetic.

\section{Reenactment in the Sound Era: RAdio PATroL}

It was not only serials of the silent era that thrived on repetition and reenactment. The sound-era serial RAdio PATrol (Universal, 1937) particularly depends on reenactment to organize its narrative, focus its plot, and reduce the number of names on its list of murder suspects. The twelve-chapter serial tells the story of Officer Pat O'Hara (Grant Withers) who, with the help of his police squad the 'radio patrol', chases the murderer of an inventor who recently developed a formula for the manufacture of flexible, bulletproof steel. Together with the inventor's orphaned son Pinky Adams (Mickey Rentschler), officer O'Hara searches for the lost formula among both steel mill owners and supposed representatives of the Iranian government lodging in the city's Egyptian quarter. The serial establishes its central conflict in a key scene in episode one, in which the inventor is shot at his desk in his laboratory ('A Million Dollar Murder'). The relevance of this scene for 
later episodes is comparable to the function of the power engine test in THE POWER GOD: its reenactments anchor the narrative and reestablish the serial's central problem, mystery, or quest. RADIO PATROL reenacts the original murder scene three times, in episodes seven, eleven, and in the final episode. Neither the original murder scene nor its reenactments enable the audience to identify the killer; however, episode one establishes multiple characters as suspects, and each reenactment reduces their number.

The first reenactment occurs in episode seven, after five episodes in which O'Hara, his sidekick officer Sam Maloney (Adrian Morris) and Pinky drive back and forth between police headquarters, the Egyptian Quarter, the city dump where Pinky lives in a shanty, and the offices of two steel mills. Whereas their investigation and pursuits eventuate plenty of thrills and sensations, their investigation fails to progress. They do, however, imprison Harry Selkirk (Max Hoffman Jr.), who stole the secret formula from the corpse but denies being the murderer. Instead, Selkirk explains to O'Hara: 'If I could get back into Adams' research laboratory and reenact the crime, I'm sure I could get the clue of the real murderer'. The result is a re-staging of the murder, in which Selkirk takes the dead man's place at the laboratory desk and O'Hara takes the position earlier occupied by Selkirk. The latter is shot dead right when he is about to identify the killer: 'O'Hara, I've got it! The shot that killed Adams came from...' (episode 7, 'Claws of Steel').

Whereas Selkirk is quite literally deleted from the suspect list, the narrative contextualization of the scene establishes three other suspects and thus effectively reboots the investigation. Instead of contemplating the reenactment, O'Hara immediately chases one of the steel mill workers through the factory, allowing the episode to conveniently recycle footage of machines and glowing, melted steel from the cliffhanger that followed the first murder in episode one. Whereas the reenactment thus benefits the investigation only marginally, it is economically convenient for the producers, and it provides the audience with a clue that emerges from their comparison of the original and the reenacted scenes.

The reenactment of the murder thus results in a second death, reactualizing the original riddle and presenting a new one at the same time. The serial thereby establishes its past problem anew in the present, replacing the first murder and simultaneously stressing its relevance. The forward momentum of the serial, its achievement in the crime solution process, therefore lies not in a return to but in a reenactment of the original crime - progress through narrative loops, so to speak. Until episode seven, most of the serial's action hinges upon the pursuit of Selkirk. His passing reboots the narrative but once again leads to frantic chases and chaotic 
pursuits. Although reenactment finally allows for some progress in the investigation, it also sparks new haywire action.

Before ending the serial with two further reenactments of this set-up, RADIO PATROL continues to eliminate murder suspects in accidents or shootings among the criminals, resulting in an overall body count of nine, which outdoes many other film serials. One of these deaths occurs in another reenacted scene from the serial's first episode, in which officers O'Hara and Maloney pursue an unknown character in a patrol car after the attempted robbery of the steel formula from the inventor's shanty at the city dump. The policemen speed down a road towards a railroad crossing when an approaching train blocks their pursuit (episode 1, 'A Million Dollar Murder'). Episode eight reenacts this instance in a sequence that recycles footage of the cars, the train, and the road from the earlier instance. This time, the officers tail the car of a private detective who, running a bit late in comparison to the first episode, dies when his car collides with the train. This instance combines reenactment with outbidding in terms of both violence and morbidity, the latter because O'Hara decides to pose as the deceased (episode 8, 'A Perfect Crime'). Like practices of outbidding more generally (cf. Jahn-Sudmann \& Kelleter 2012), the reenactment of the instance combines an emotional or affective pressurization with signals of self-consciousness and a tendency towards irony. Reenactment both intensifies suspense and foregrounds narrative structuring, resulting in the simultaneity of self-awareness and invested engagement that informs the operational aesthetic. RADIO PATROL thus repeatedly points to the processuality of its neatly corresponding but nevertheless chaotically meandering causes and effects, and the serial's plot twists and circles back to the reenactments that anchor its processual frenzy.

The serial's final deaths result again from reenactments of the inventor's murder at his desk. In the eleventh episode, O'Hara's pursuit of the Iranian government agent known as Mr. Tahata ends in the laboratory, where Tahata claims innocence and - as in the earlier scene-is shot before he can identify the murderer (episode 11, 'The Hidden Menace'). This reenactment is substantially shorter than the earlier one, and it occurs accidentally rather than carefully planned. Nevertheless, it recalls and returns to the setting of the story's original problem. In fact, in establishing that Tahata did not plan to arrive at the laboratory at this moment, the reenactment of the scene establishes the possibility that the solution to the case lies within the laboratory space itself rather than in the search for possible murderers and motives.

Again corresponding to a logic of outbidding, the twelfth episode places two characters in succession in the deadly position in the research laboratory. 
Zutta (Dick Botiller), a henchman of Tahata's, ${ }^{32}$ attempts to blackmail the steel-mill owner Wellington in the laboratory and is shot near the desk, this time with no possible murder suspect waiting nearby. Wellington hides the body and begins to readjust a hidden mechanism in the wall: a mechanical gun contraption that we now learn killed all four of the victims (episode 12, 'They Get Their Man'). The scene thus confirms the mechanical nature of the threat, which was already foreshadowed by the lack of suspects in the latest murder and the similarity of physical circumstances. The resolution of the case follows just a few moments later, when O'Hara returns to the laboratory and has Wellington at gunpoint, who then explains his contraption..$^{33}$ In a struggle with O'Hara, Wellington is killed by his own shooting mechanism (episode 12, 'They Get Their Man').

Whereas the first reenactment in episode seven effects a reboot of both the narrative and the investigation, the later laboratory shootings constitute repetitive instances that, as bodies pile up, intensify the problem to be solved. The serial itself addresses this intensification when early on in the final episode, O'Hara's superior threatens to take O'Hara off the case and revoke his recent promotion to the plainclothes squad because the case was still unsolved and the number of deaths had accumulated (episode 12, "They Get Their Man'). The increase of murders and their recurrence in shorter intervals towards the serial's end point towards the relation of reenactment and the mechanical nature of the threat, establishing repetitious occurrences as intrinsically machinic. As if to counteract this threatening depiction of the mechanical, the final episode ends with a shot of the faultlessly functioning steam engine that Pinky built or repaired at the city dump, which exploded in the ninth-episode cliffhanger ('Plaything of Disaster'). Whereas the fatal impact of the automatic gun contraption is irreversible, the engine can, luckily, be fixed. The steam engine thus effects the final revision of an earlier scene, representing a return to normalcy in the end.

In summary, the reenacted instances in RADIO PATROL encourage viewers to understand the serial apart from the chronological screening of its episodes. Viewers correlate and compare instances across the serial's dozen episodes and thereby identify the serial's centralized threat as a machinic

32 Earlier in episode twelve, it was revealed that the man calling himself Tahata was really 'Warner the Great', a famous hypnotist who kept the real Mr. Tahata under his spell ('They Get Their Man'). The character who throughout the serial was thought to be Tahata's hypnotized henchman, Franklin, reveals himself to be the real Mr. Tahata, a representative of the Iranian government with no evil intent.

33 The set-up involves an invisible light beam that, once broken by someone standing next to the laboratory desk, triggers the shooting mechanism. 
contraption. The reenactments uncover the machinic cause of the murders, and they simultaneously expose the film serial as a similarly repetitious machine. Instead of boring viewers, the frequent returns to the same spaces and plots propel the narrative and enable the eventual solution of the serial's central mystery. Viewers do not enjoy the serial despite its multiple forms of reprise with their obvious economic advantages to the film producers. On the contrary, repetitions and reenactments enable and encourage viewers to uncover the working of both the serial's diegetic death contraption and its narrative structure and organization, inviting and fostering acts of operational detection. As a result, RADIO PATROL offers its viewers a subject position that is neither fully immersed nor alienated and that diverts from the model of the classical Hollywood film.

\section{Intermediate Afterword: The Serials' Self-Conscious Negation of Classicality}

As the four examples above have shown, repetitions, reiterations, and reenactments invite a viewing practice that departs from a chronological following of events as they occur from episode to episode. Viewers draw parallels and cross-reference sequences across multiple episodes, which are at times screened weeks apart from each other. Individual scenes refer to a past moment in the serial and re-actualize it, locating the ongoing action - including its narrative past - firmly in the present tense. A return to earlier scenes of origination effectively and self-consciously anchors narratives that operate according to a principle in which causes and effects follow one another without leading anywhere. Whereas examples of the careful hiding of recycled footage abound in film serials, moments of reenactment depend on the viewer noticing repeat footage and identifying a scene as reenacted. After all, it is the repeated use of footage, sets, and plots that urges viewers to draw the connections, to compare, and to contrast. This activity of operational detection effects a co-occurrence of self-conscious and intensified storytelling, which encourages viewers to critically assess the serial's narrative formula while enjoying its rehearsal.

As pointed out earlier, this activity of operational detection is located halfway between alienation and full immersion, negating both conceptual extremes and constituting a midway alternative instead. And film serials are very much aware of their own unwillingness to construct verisimilar, immersive filmic environments. This awareness manifests itself in the first episodes of many serials, which are often longer than the ensuing ones and 
offer narrative structures that resemble more narratively contained forms. Scott Higgins highlights the importance of a serial's initial episode in the sound era, when 'the first chapter was vital to the serial's market identity' (2016: 38). Until the mid-1940s, film serials commenced their narratives with longer 'pilot' episodes that lasted about 30 minutes as opposed to the standard 18 to 20 and that include more detailed plot expositions and costlier and more spectacular stunts. These expository episodes at times feature montage sequences that place their ensuing narrative in a larger historical, political, or otherwise discursive context. This broadness of scope, Higgins argues, resembles the opening acts of Hollywood features and stands in contrast to the repetitive, focused, and condensed narratives of a serial's remaining episodes (pp. 38-43).

These observations similarly hold true for a number of silent-era serials. Although their style and formula are less static than in the sound era, silent serials often begin with introductory episodes that differ markedly from the serial's following installments in terms of viewer address and their mode of storytelling. These episodes align themselves with self-contained narratives, only to discard this narrative mode as inappropriate for film serials. Subsequent episodes thus abandon the initial approach and instead embark on the seemingly open-ended rollercoaster rides that this chapter outlined. The Perils of Pauline (Pathe, 1914) for instance, begins, like many serials of the time, with the death of the heroine's father. The tragic tableau of characters behind the old man's deathbed strikes an emotional tone that none of the following episodes recreate. Additionally, the episode portrays the villainous figure of Koerner (Paul Panzer) as a conflicted character who is blackmailed by the wholeheartedly sinister crook Hicks into pursuing the death of Pauline (Pearl White). In the Manichean struggle of good versus evil enacted in the succeeding episodes, Koerner's initial inner conflict goes entirely unmentioned. The serial thus initially offers a plausible reason for Koerner's actions, providing what Bordwell terms 'realistic motivation' for this character's behavior, whereas ensuing episodes eschew any psychologizing and in fact display the villain's evil intentions to an extent that runs against the motivation originally provided (Bordwell et al. 1985: 19). The initial episode of THE PERILS OF PAULINE therefore exceeds the serial's following episodes in emotional depth, and its more complex psychology results in a markedly different film experience.

The film serials discussed in this chapter similarly offer more pathos and character motivation in their initial episodes than in succeeding ones. The introductory episode of THE HOPE DiAmOND MYsTERY prefigures parts of the story set in sixteenth-century Burma to motivate its narrative, and THE 
POWER GOD begins with Aileen's father's rejection of Jim's proposal to marry his daughter and the father's tragic death. While these episodes establish emotional and causal plot motivation, later episodes do without grief and anger and instead present the serial's Manichean conflict as a given.

OFFICER 444 begins with a pilot episode that differs particularly radically from its ensuing episodes: it depicts the protagonist officer as the all-American hero who saves a child and a known criminal from a burning building after the firefighters have withdrawn. 444 is a highly individualized and self-dependent character, a popular hero called 'Uncle Bob' by the children in the street (episode 1, 'The Flying Squadron'). Especially the shots of the child wandering through the burning house enact the melodramatic fear of the 'too late' and eventually foster the affects that result from a rescue 'in the nick of time' - a strategy the film serial will confine to cliffhangers in all following installments. By episode two, 'Uncle Bob' will be '444', a number in the systemized machine of the police, a team player, one cogwheel in the larger mechanism. This shift epitomizes the serial's discarding of its early immersive appeal in favor of a presentational mode of address. However, this shift describes the change of an underlying norm rather than a turn from one extreme to another: Hollywood's norm of storytelling as described by Bordwell, Thompson, and Staiger, for instance, generally and generically includes 'laying bare the device', fostering an awareness of its principles of narrative and medial construction. However, the Hollywood feature 'does not bare its devices repeatedly and systematically' (Bordwell et al. 1985: 22-23).

It is just this notion of repetition and a systematic reflection of storytelling principles that characterizes the serials' presentationalism. The comparison between the serials and the 'classical' feature, which the serials themselves enacted when initially evoking and then discarding established norms, is thus based on the identification of the previous common exception as a rule, that is, on an inversion of the relationship between ongoing narrative strategy and momentary deviation. For serials as well as for early and transitional-era film in general, the possibility of an immersive engagement with film was a persistent undercurrent that informed filmic practices and aesthetics even in films that revoke immersion, as Denson argues (2014a:63-66). Similarly, studio-era features seemed to accept what Jay David Bolter and Richard Grusin term 'immediacy' as a norm, although 'there are moments in which hypermediacy interrupts the aesthetic of transparency' (1999: 150-151). Serials thus inverted a figure-ground relationship, and they explicitly addressed the fact that they did. They retained this aversion and neglect throughout the silent era, repeatedly voicing their discontent decade after decade. Despite their openly staged neglect, it seems that serials could 
not fully disassociate themselves from the contemporaneous mainstream. As a consequence, their presentational filmic narratives always existed at the nexus of immersion and self-reflexivity. As the following chapter will outline, it is this presentational style and complex subject position that enabled serials to navigate the multiplicity of media, particularly radio and television, in the sound era.

\section{Bibliography}

A Mistaken Calling. Dir. unknown. Perf. Eleanor Blanchard, Howard Missimer, John Steppling. Essanay, 1912.

Bordwell, David, Janet Staiger, and Kristin Thompson. 1985. The Classical Hollywood Cinema: Film Style and Mode of Production to 196o. London: Routledge.

Brasch, Ilka, and Ruth Mayer. 2016. "Modernity Management: 1920s Cinema, Mass Culture and the Film Serial." Screen 57 (3).

Canjels, Rudmer. 2011. Distributing Silent Film Serials: Local Practices, Changing Forms, Cultural Transformation. Routledge Advances in Film Studies 7. New York: Routledge.

Cole, Simon A. 2001. Suspect Identities: A History of Fingerprinting and Criminal Identification. Cambridge, MA: Harvard University Press.

Denson, Shane. 2014. Postnaturalism: Frankenstein, Film, and the Anthropotechnical Interface. Bielefeld: transcript.

Exhibitor's Herald. 1921. “David P. Howells Obtains Right on Darmond Serial, 'Hope Diamond Mystery," February 26.

Flash Gordon. Dir. Frederick Stephani. Perf. Buster Crabbe, Charles M. Middleton, Jean Rogers. Universal, 1936.

Fowler, Marian. 2002. Hope: Adventures of a Diamond. Sydney and London: Simon \& Schuster.

Frankenstein. Dir. James Whale. Perf. Mae Clarke, Colin Clive, Boris Karloff. Universal, 1931.

Goldman, Harry. 2005. Kenneth Strickfaden, Dr. Frankenstein's Electrician. Jefferson, MC: McFarland.

Gunning, Tom. 1986. “The Cinema of Attraction: Early Film, Its Spectator and the Avant-Garde.” Wide Angle 8 (3-4): 63-70.

- 1993. "Now You See It, Now You Don't': The Temporality of the Cinema of Attractions." The Velvet Light Trap 32 (2): 3-12.

—. 1994. "The Whole Town's Gawking: Early Cinema and the Visual Experience of Modernity." The Yale Journal of Criticism 7 (2): 189-201.

- 2004. "Systematizing the Electric Message: Narrative Form, Gender, and Modernity in The Lonedale Operator." In American Cinema's Transitional Era:Audiences, Institutitons, Practices, edited by Charlie Keil and Shelley Stamp, pp. 15-50. Berkeley: University of California Press.

Haenni, Sabine. 2015. "Gender in the Jungle." Conference: Managing Mass Culture. April 25. Hannover.

Hansen, Miriam. 1994. Babel and Babylon: Spectatorship in American Silent Film. Cambridge, MA: Harvard University Press.

Hidden Dangers. Dir. William Bertram. Perf. Jean Paige, Joe Ryan, George Stanley. Vitagraph, 1920. Higgins, Scott. 2016. Matinee Melodrama: Play and the Art of Formula in the Sound Serial. New Brunswick: Rutgers University Press. 
Intolerance. Dir. D. W. Griffith. Perf. Lillian Gish, Mae Marsh, Constance Talmadge. D. W. Griffith/Triangle, 1916.

Jahn-Sudmann, Andreas, and Frank Kelleter. 2012. "Die Dynamik Serieller Überbietung: Amerikanische Fernsehserien Und Das Konzept Des Quality-TV." In Populäre Serialität: Narration - Evolution - Distinktion: Zum Seriellen Erzählen Seit Dem 19. Jahrhundert, edited by Frank Kelleter, pp. 205-24. Bielefeld: transcript.

Keil, Charlie. 2006. “Integrated Attractions: Style and Spectatorship in Transitional Cinema.” In The Cinema of Attractions Reloaded, edited by Wanda Strauven, pp. 193-203. Amsterdam: Amsterdam University Press.

Kelleter, Frank, Ruth Mayer, and Barbara Krah, eds. 2007. Melodrama! The Mode of Excess from Early America to Hollywood. Heidelberg: Universitätsverlag Winter.

King, Rob. 2009. The Fun Factory: The Keystone Film Company and the Emergence of Mass Culture. Berkeley: University of California Press.

Loock, Kathleen. 2016. "Sound Memories: 'Talker Remakes,' Paratexts, and the Cinematic Past." In The Politics of Ephemeral Digital Media: Permanence and Obsolescence in Paratexts, edited by Sara Pesce and Paolo Noto, pp. 123-137. New York: Routledge.

Mayer, Ruth. forthcoming. "In the Nick of Time? Detective Serials, Temporality, and Contingency Management, 1919-1926."

- 2014. Serial Fu Manchu: The Chinese Supervillain and the Spread of Yellow Peril Ideology. Philadelphia: Temple University Press.

Moving Picture World. 1912. "A Mistaken Calling (Essanay)," October 19.

Musser, Charles. 2006. "A Cinema of Contemplation, A Cinema of Discernment: Spectatorship, Intertextuality and Attractions in the 189os." In The Cinema of Attractions Reloaded, edited by Wanda Strauven, pp. 159-79. Amsterdam: Amsterdam University Press.

New York Tribune. 1918. "In Vaudeville," March 10, 1918.

Noah's Ark. Dir. Michael Curtiz. Perf. Noah Beery, Dolores Costello, George O'Brien. Warner Bros., 1928.

Nye, David E. 1990. Electrifying America: Social Meanings of a New Technology, 1880-1940. Cambridge, MA: The MIT Press.

Officer 444. Dir. Francis Ford. Perf. Al Ferguson, Neva Gerber, Ben Wilson. Ben Wilson/Goodwill, 1926.

Picture-Play Magazine. 1919. "Relished by the Best of Men," February.

Poe, Edgar Allan. 1841. "The Murders in the Rue Morgue." In The Works of Edgar Allan Poe, Vol. 1, edited by John H. Ingram, pp. 404-41. London: A\&C Black.

Projansky, Sarah. 2001. Watching Rape: Film and Television in Postfeminist Culture. New York: New York University Press.

Radio Patrol. Dir. Ford Beebe and Cliff Smith. Perf. Catherine Hughes, Mickey Rentschler, Grant Withers. Universal, 1937.

Schaschek, Sarah. 2013. Pornography and Seriality: The Culture of Producing Pleasure. London: Palgrave Macmillan.

Singer, Ben. 2001. Melodrama and Modernity: Early Sensational Cinema and Its Contexts. New York: Columbia University Press.

The Adventures of Kathlyn. Dir. Francis J. Grandon. Perf. Charles Clary, Lafe McKee, Kathlyn Williams. Selig, 1913.

The Amazing Exploits of the Clutching Hand. Dir. Albert Herman. Perf. Rex Lease, Ruth Mix, Jack Mulhall. Weiss, 1936.

The Black Box. Dir. Otis Turner. Perf. Ann Little, Herbert Rawlinson, William Worthington. Universal, 1915. 
The Black Diamond Express. Dir. James H. White. Edison, 1896.

The Exploits of Elaine. Dir. Louis J. Gasnier, George B. Seitz, Leopold Wharton, and Theodore Wharton. Perf. Arnold Daly, Creighton Hale, Pearl White. Pathe, 1914-1915.

The Great Radium Mystery. Dir. Robert Broadwell, Robert F. Hill. Perf. Cleo Madison, Bob Reeves, Eileen Sedgwick. Universal, 1919.

The Hazards of Helen. Dir. J.P. McGowan, James Davis. Perf. Helen Gibson, Helen Holmes. Kalem, 1914-1917.

The Hope Diamond Mystery. Dir. Stuart Paton. Perf. George Chesebro, Grace Darmond, Boris Karloff. Kosmik, 1920.

The Lonedale Operator. Dir. D. W. Griffith. Perf. Verner Clarges, Guy Hedlund, Blanche Sweet. Biograph, 1911.

The Lone Ranger. Dir. William Witney, John English. Perf. Lee Powell, Hal Taliaferro, Chief Thundercloud. Republic, 1938.

The Lost City. Dir. Harry Revier. Perf. William 'Stage' Boyd, Claudia Dell, Kane Richmond. Krellberg, 1935 .

The Mask of Fu Manchu. Dir. Charles Brabin. Perf. Boris Karloff, Myrna Loy, Lewis Stone. Cosmopolitan/MGM, 1932.

The Million Dollar Mystery. Dir. Howell Hansel. Perf. Florence La Badie, James Cruze, Marguerite Snow. Thanhouser, 1914.

The Mystery Ship. Dir. Harry Harvey, Henry McRae. Perf. Neva Gerber, Ben F. Wilson, Duke Worne. Universal, 1917.

The New Exploits of Elaine. Dir. Louis J. Gasnier, Leopold Wharton, Theodore Wharton. Perf. Arnold Daly, Creighton Hale, Pearl White. Pathe, 1915.

The Perils of Pauline. Dir. Louis J. Gasnier and Donald MacKenzie. Perf. Paul Panzer, Pearl White, Crane Wilbur. Eclectic/Pathe, 1914.

The Perils of Nyoka. Dir. William Witney. Perf. Kay Aldridge, Lorna Gray, Clayton Moore. Republic, 1942.

The Power God. Dir. Francis Ford. Perf. Al Ernest Garcia, Neva Gerber, Ben Wilson. Ben Wilson/ Goodwill, 1925 .

The Romance of Elaine. Dir. George B. Seitz, Leopold Wharton, Theodore Wharton. Perf. Arnold Daly, Creighton Hale, Pearl White. Pathe, 1915.

The Screaming Shadow. Dir. Ben F. Wilson, Duke Worne. Perf. Neva Gerber, Ben F. Wilson. Hallmark, 1920.

The Trail of the Octopus. Dir. Duke Worne. Perf. William Dyer, Neva Gerber, Ben F. Wilson. Hallmark, 1919.

The Vanishing Shadow. Dir. Lew Landers. Perf. James Durkin, Ada Ince, Onslow Stevens. Universal, 1934.

The Voice from the Sky. Dir. Ben F. Wilson. Perf. Neva Gerber, Wally Wales, Robert Walker. Hollywood, 1930.

The Voice on the Wire. Dir. Stuart Paton. Perf. Neva Gerber, Joseph W. Girard, Ben F. Wilson. Universal, 1917.

Three Ages. Dir. Buster Keaton. Perf. Wallace Beery, Buster Keaton, Margaret Leahy. Metro Pictures, 1923.

Variety. 1915. "Bills Next Week (January 4)," January 1.

-. 1918. "Bills Next Week (March 11)," March 8.

What Happened to Mary. Dir. Charles Brabin and Ashley Miller. Perf. Mary Fuller, Marc McDermott, Charles Ogle. Edison, 1912. 
Whissel, Kristen. 2008. Picturing American Modernity: Traffic, Technology, and the Silent Cinema. Durham and London: Duke University Press.

Who Will Marry Mary? Dir. unknown. Perf. Mary Fuller, Ben. F. Wilson, Richard Tucker. Edison/ General, 1913 .

Williams, Linda. 1991. "Film Bodies: Gender, Genre, and Excess." Film Quarterly 44 (4): 2-13.

—. 1998. "Melodrama Revised." In Refiguring American Film Genres: History and Theory, edited by Nick Browne, pp. 42-88. Berkeley and Los Angeles: University of California Press.

Wolves of Kultur. Dir. Joseph A. Golden. Perf. Leah Baird, Sheldon Lewis, Charles Hutchinson. Western Photoplays, 1918. 
